\title{
التثوهات المعرفية وعلاقتها بجودة الحياة لدى طلبة الصف الثاني الثانوي العام
}

\section{مقدمة}

لاشكك أن المعرفة والأفكار تجعل الانسان يكتسب مشاعر معينة، وإدراكنا لهذه المشاعر

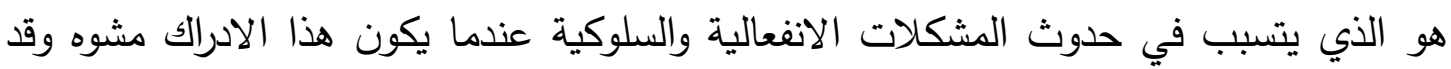

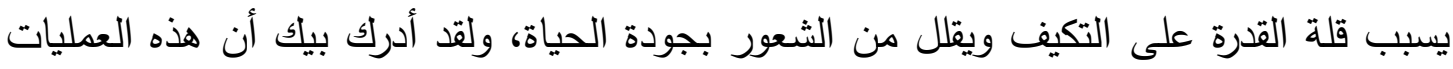

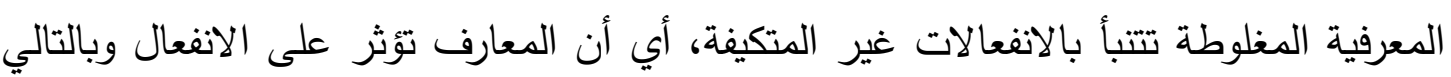

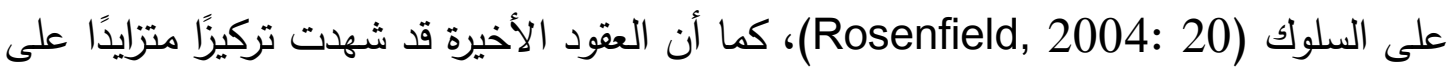
استخدام النموذج المعرفي لشرح المشكلات "الانفعالية، والسلوكية"، مثل الارتباط بالإدراك المشوده، لفهم وتفسير السلوك والشخصية، وتأثير ذلك على حياة الفرد (Ara, 2016: 706). وحيث أن التشوهات المعرفية تتميز بالسلبية في تفسير الأحداث والتي لا تستتد على أساس لفاس

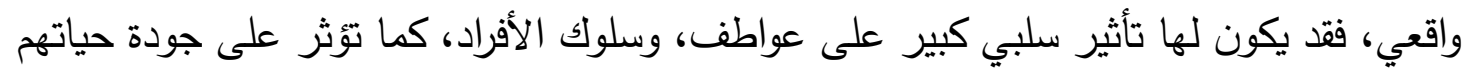
وتكيفهم بالسلب (Pereira, 2012:817). وحيث أن التشوه المعرفي يعوق الإنسان في إدراكه، فالإنسان في هذه الحالة يحمل أحكامًا سلبية مسبقة عن الموقف، ومعلومات لا يحكمها المنطق،

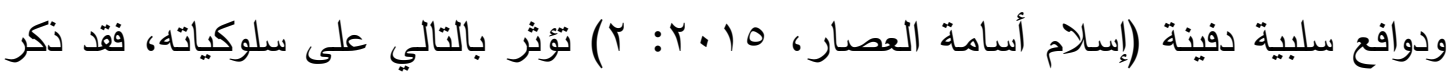
"آرون بيك" في أن النظرية المعرفية تقترح أن التصورات السلبية للفرد يمكن أن تعكس التشوهات

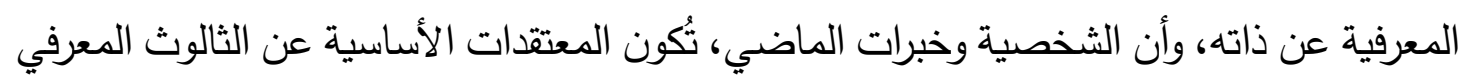

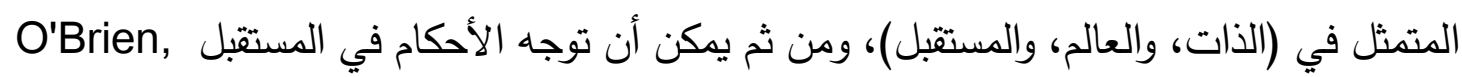
.(2016: 25)

وحيث أن التشوه المعرفي يشوش إدراك الفرد، فإنه يعوق التفاعل الجيد، والقرار المناسب،

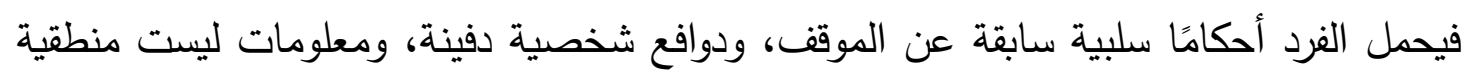

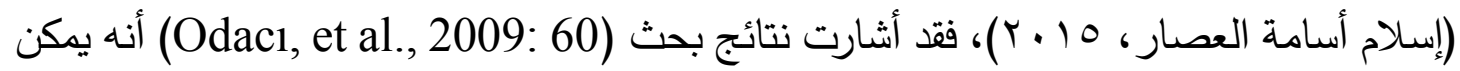
التنبؤ بجودة الحياة من خلال مستوى التشوهات المعرفية، حيث توجد علاقة سالبة بين التشوهات المعرفية وجودة الحياة. وأيد وجود ارتباط سالب دال إحصائيًا بين أبعاد جودة الحياة والتشوهات

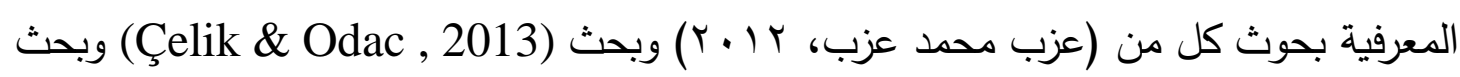

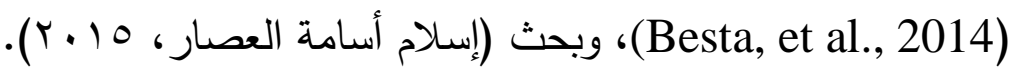

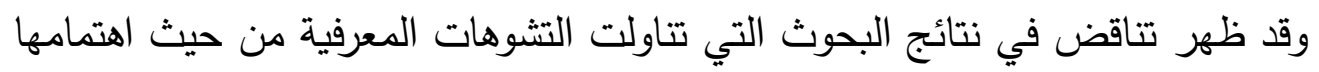

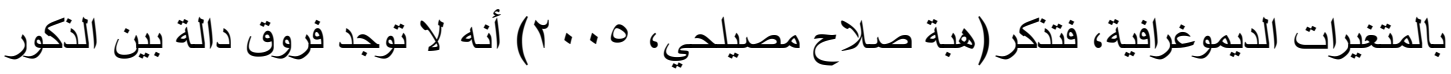
والإناث في التشوهات المعرفية، وأيد هذه النتيجة بحث كل من (Bruno , 2010)، (نهلة نجم 


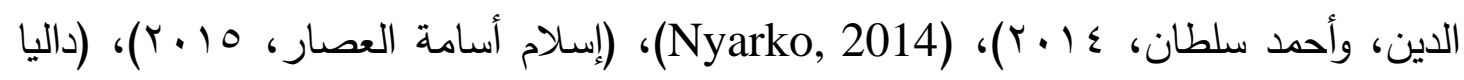

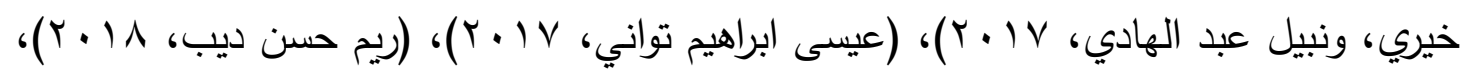

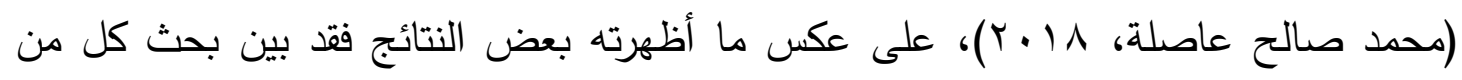

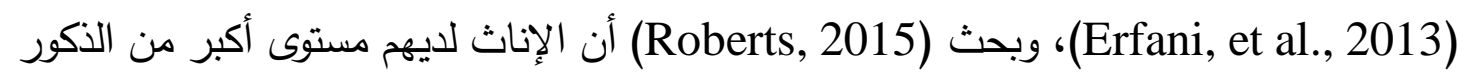

في التشوهات المعرفية.

بينما على النقيض من النتائج السابقة فقد أوضحت بحوث كل من (ابتسام محمد ابراهيم،

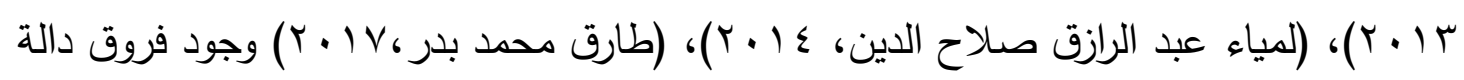

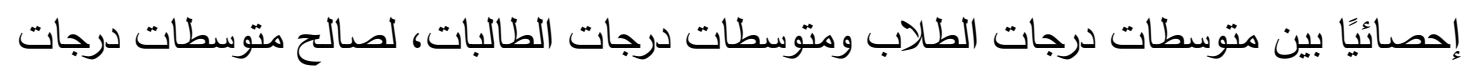

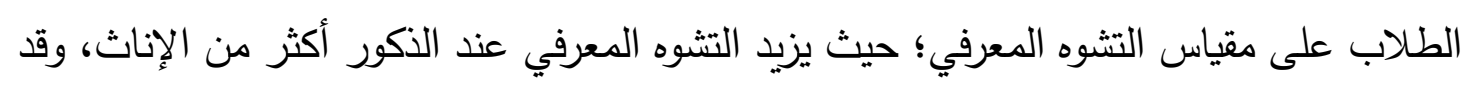

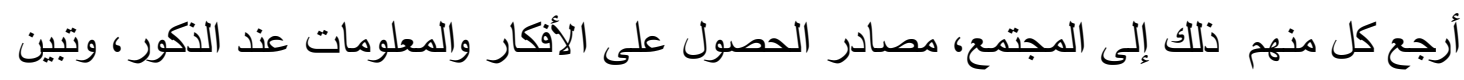

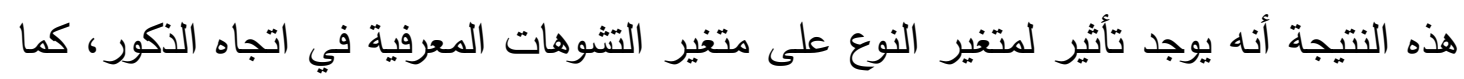

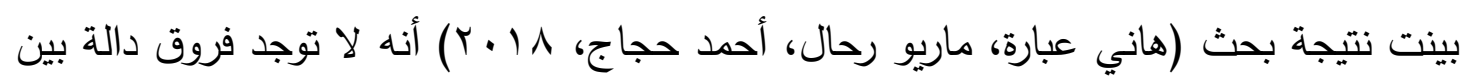

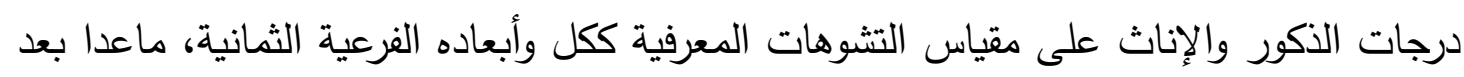

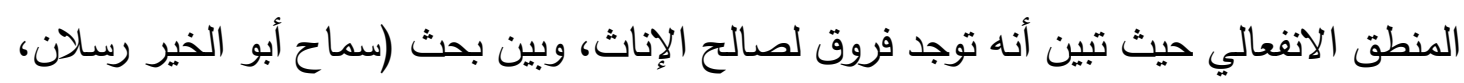

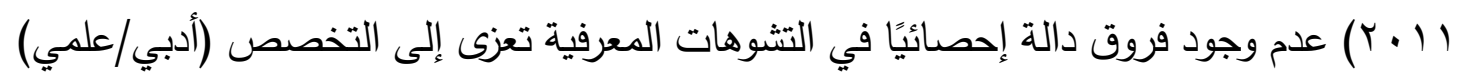

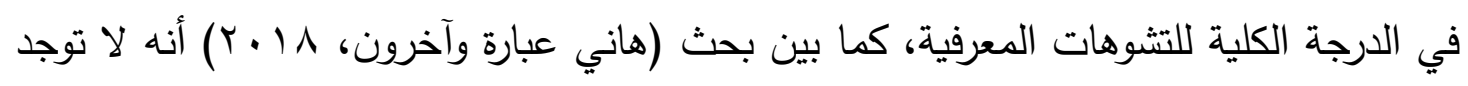
فروق دالة بين طلبة الفرع العلمي، والتخصص الأدبي في مقياس التشوهات المعرفية ككل وأبعاده

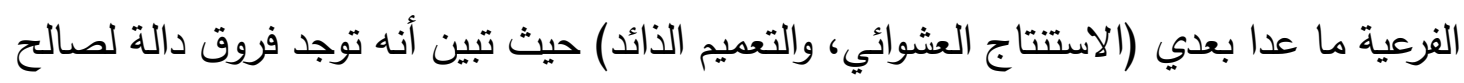

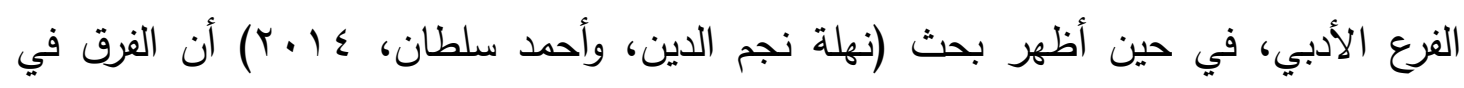

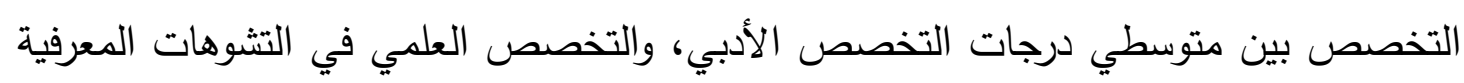

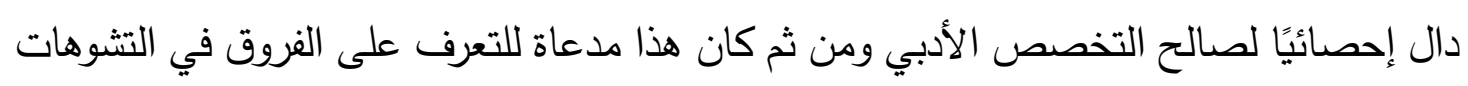
المعرفية وكنللك كتغيرات البحث مجتمعة والتي ترجع إلى النوع والتخصص التص هان الدراسي.

ويتبين من خلال العرض السابق مدى تباين النتائج ومدى ارتباط الموضوع الحالي

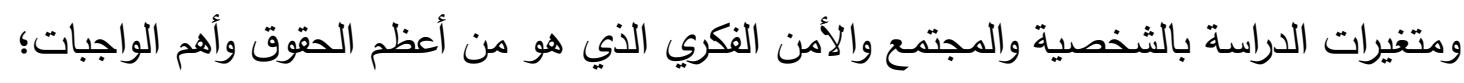

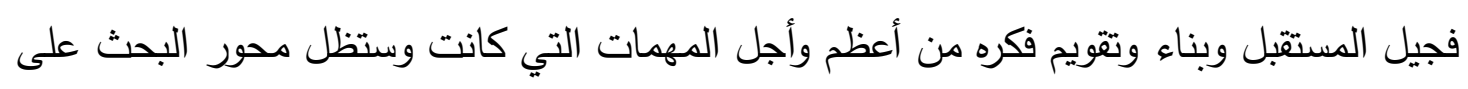

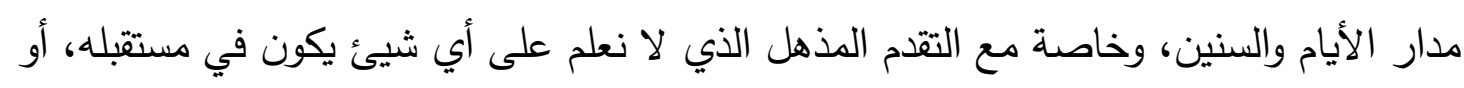

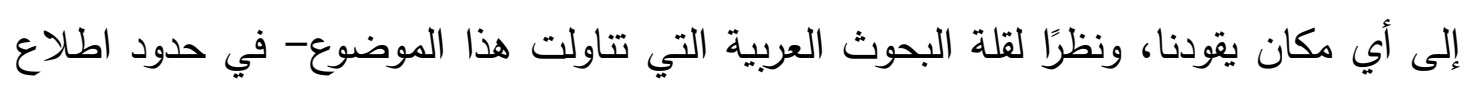

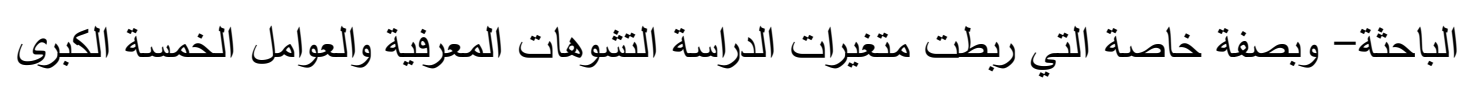
للشخصية وجودة الحياة، وانطلاقًا من هنا كان الدافع لإجراء الدراسة وأهمية إجراءها. 


\section{ويمكن صياغة مشكلة البحث في الأسئلة التالية:}

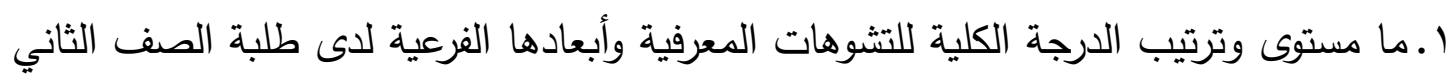

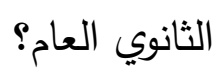

r. هل تختلف درجات التشوهات المعرفية باختلاف النوع (ذكور / إناث) لدى طلبة الصف الثاني

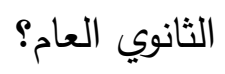

r. هل تختلف درجات التشوهات المعرفية باختلاف التخصص(علمي/أدبي) لاى طلبة الصف الصف

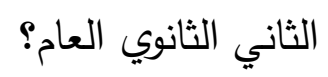

ـ. هل يوجد ارتباط بين درجات التشوهات المعرفية وجودة الحياة لدى طلبة الصف الثاني الثانوي

$$
\text { العام؟ }
$$

$$
\text { ثالثًا: أهداف البحث: العث }
$$

1- التعرف على مستوى الدرجة الكلية للتشوهات المعرفية وأبعادها الفرعية لدى طلبة الصف الصف

$$
\text { الثاني الثانوي العام }
$$

r- بحث الفروق بين طلبة الصف الثاني الثانوي العام في التشوهات المعرفية التي ترجع إلى الى

$$
\text { بعض المتغيرات الديموغرافية (النوع، والتخصص الدراسي). }
$$

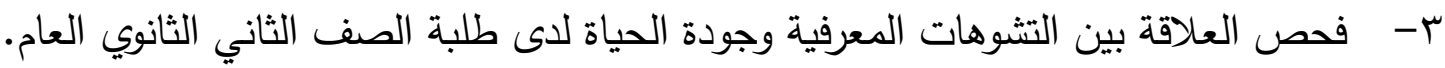

$$
\text { رابعًا: أهمية البحث: }
$$

ا ـ تزويد المكتبة العربية ببعض المفاهيم النفسية مثل التشوهات المعرفية وجودة الحياة. r. محاولة إثراء المكتبة النفسية والتربوية من خلال تقديم إطارًا نظريًا لمتغيرات البحث (التشوهات المعرفية، جودة الحياة) والذي لاقى القليل من الاهتمام من الباحثين.

(ب) الأهمية التطبيقية: (ب)

ا. يمكن أن تسهم نتائج الدراسة الحالية في تصميم برامج معرفية سلوكية لتحسين جودة الحياه

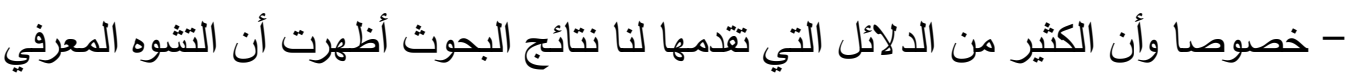
يمكن أن يتم استبداله بتفكير منطقي عقلاني. 
r. قد تساعد نتائج البحث الجهات المعنية في الاهتمام بإدراج موضوعات تخدم التفكير العقلاني في المقررات الدراسية بما يتلاءم مع نموهم العقلي. r. قد يفيد البحث الحالي أولياء الأمور والمرشدين، والمعلمين، والمربين في توضئ لوضيح التشوهات المعرفية، وإرشاد الشباب لمواجهتها ليحيوا بصورة عقلانية. خامسًا: مصطلحات البحث:

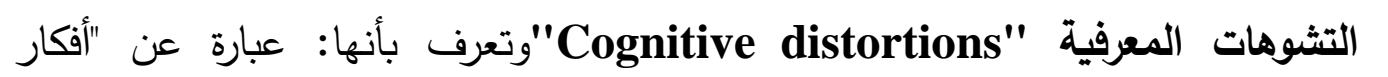

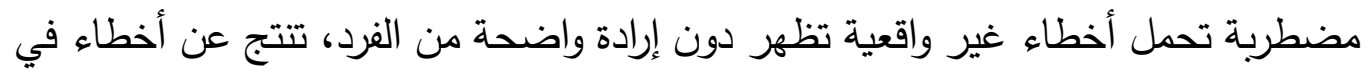

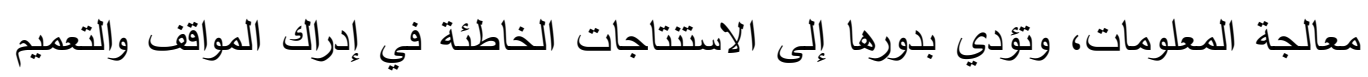

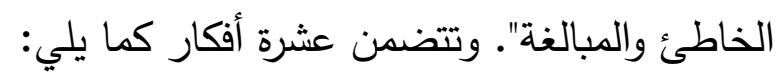
- - التفكير (الكل أو لا شيئ) المستقطب (All or nothing thinking)، الشخصنة أو اللوم

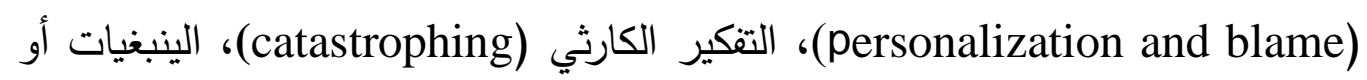
الحتميات (should or must statements) التجريد الانتقائي أو التصفية العقلية (overgeneralization) التعميم التهائد) (mental filter) (magnification\& minimization) العشوائي (Jumping to Conclusions) الحكم الانفعالي (emotional reasoning).

:Quality of Life جودة الحياة (r)

وتعرف بأنها: الاحساس الكلي بالسعادة العامة التي تتتج عن التيقيم الذاتي، والموضوعي للكفائة

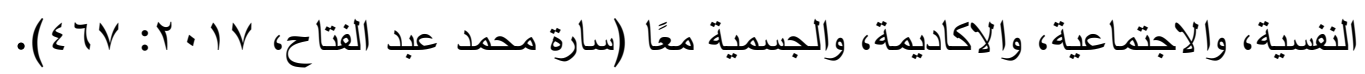

\section{ويندرج تحتها الأبعاد التالية:}

- جودة الحياة النفسية "Psychological Quality of Life": وهي إحساس عام الإد

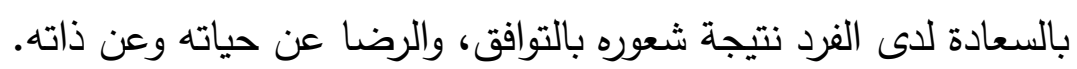

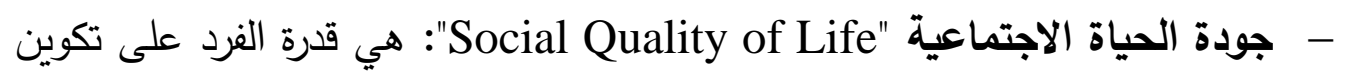
علاقات اجتماعية، و احترام مبادئ المجتمع الذي يعيش فيه، مع المشاركة الفعالة في الأي الانشطة الاجتماعية. - - جودة الحياة الأكاديمية "Academic Quality of Life": هي شعور الفرد بالرضا

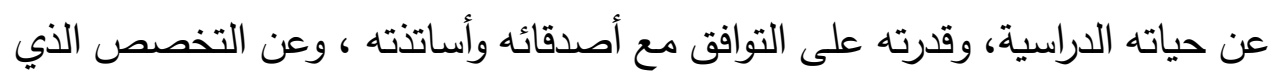
يلتحق به. 
- جودة الحياة الجسمية "Physical Quality of Life": هي ما يتمتع به الفرد من

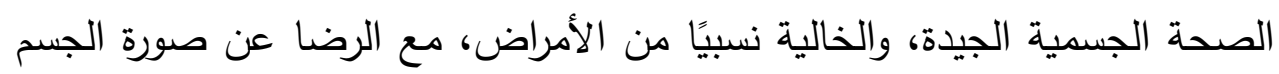

وشكله.

الإطار النظري:

أولًا: التشوهات المعرفية Cognitive Distortions:

تحتل دراسة التشوهات المعرفية أهية كبيرة ذللك لأن المعرفة تعتبر وسيلة الإنسان للتوصل إلى حقائق الأشياء، وهي سبيله إلى التعرف على ذاته والعالم، فقد ذكر (هاني عبارة وآخرون،

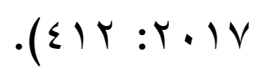

وتعتبر التشوهات المعرفية من المتغيرات النفسية التي قد يكون لها تأثير سلبي في سلوكيات الطالب والتي تؤثر وتتأثر بمتغيرات شخصيته وتؤثر في اتخاذ قراراته، كما تؤثر وتتأثر بنوعية حياته، فيرى "ويسمان، وبيك" (Weissman\& Beak, 1978:6) أن التشوهات المعرفية عبارة

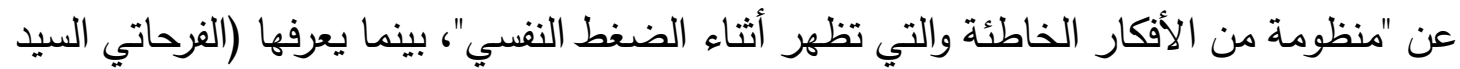

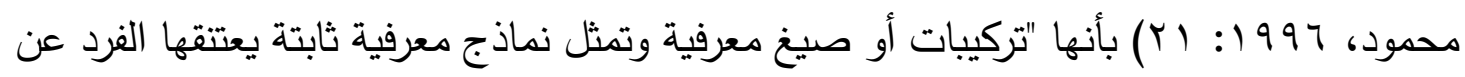
ذاته والعالم والمستقبل"، وتعرف "باريجا" (Barriga et al., 2000: 37) التشوهات المعرفية بأنها "طرق غير دقيقة في إضفاء أو معالجة المعنى بناء على الخبرة". وتعرف يوريكا (Yurica, 2002:100) التشوهات المعرفية بأنها: "أفكار تظهر تلقائيًا لاى الفرد تعمل على ضبط سلوكياته وحاجاته، ولايستطيع إيقافها، أو التحكم بها"، وتتتج عن بانسات

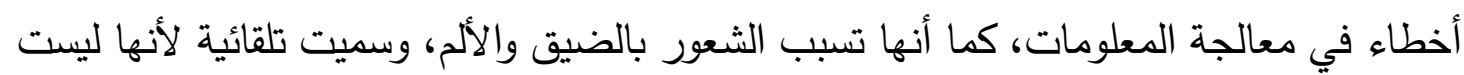

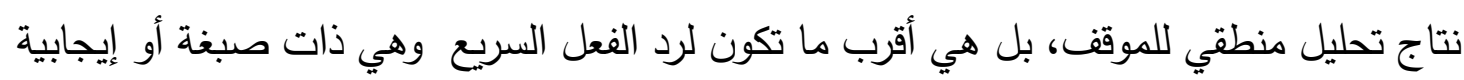
ولكنها في الغالب سلبية. وتضيف (إسلام أسامة العصار ، 10 • ب: 7 (1) بأن التشوهات المعرفية عبارة عن "أخطاء

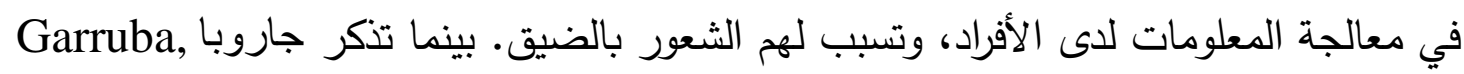

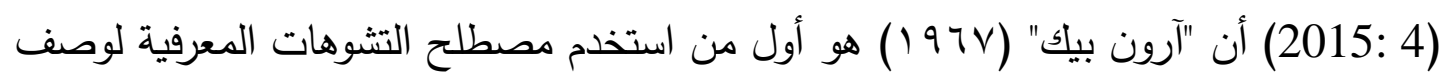
الأنماط الخاطئة في المعالجة المعرفية؛ وتمثل الافكار التي تؤدي إلى مشاعر ، وسلوكيات سلبات سلبية

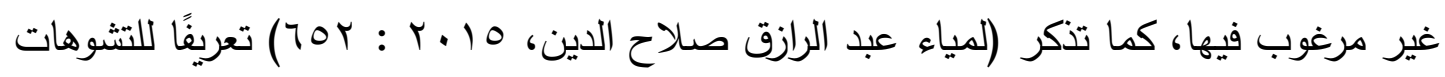

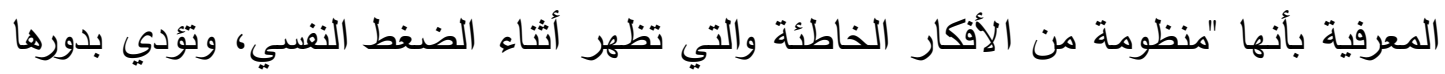

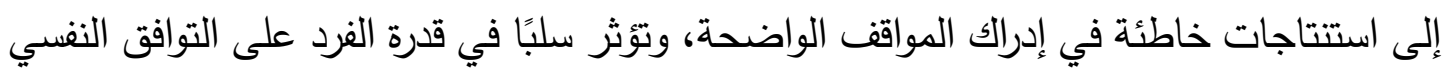
والاجتماعي"، ويذكر أوبراين (O'Brien, 2016:27) أن كل من مصطلحات "التشوهات المعرفية، 
أو الأفكار التلقائية، المعتقدات اللاعقلانية"، تستخدم بشكل متبادل للتعبير عن أخطاء في أنماط التفكير فيما يتعلق بالذات.

ويتضح مما سبق أنه تعددت التعريفات حسب وجهات نظر الباحثين؛ وبالتالي يمكن تعريف

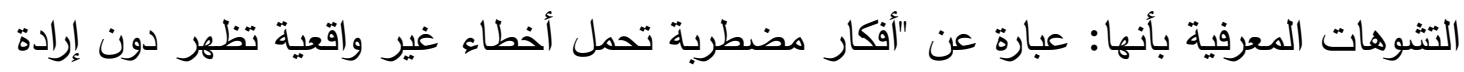
واضحة من الفرد، تنتج عن أخطاء في معالجة المعلومات، وتؤدي بدورها إلى الاستتتاجات الخاطئة في إدراك المواقف والتعميم الخاطئ والمبالغة".

ولقد حدد "ويسمان، وبيك" (1) :Weissman, Beak, 1978) عوامل التشوية المعرفي

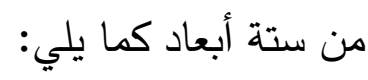

ا. التهويل "المبالغة" أو التهوين: حيث يضفي الفرد دلالات مبالغ فيها علي الموضوعات المحايدة، أوالمبالغة.

r r التعميم؛ بمعني تعميم خبرة سلبية منعزلة علي الذات ككل.

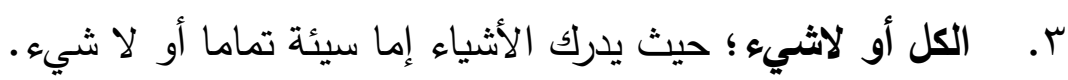

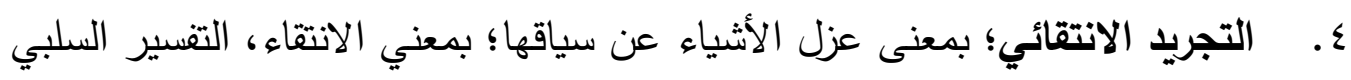
للموقف.

๑. القفز إلي الاستنتاجات؛ بمعني إدراك أن الموقف ينطوي علي خطر بدون دلائل واضحة.

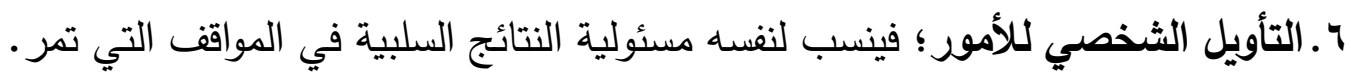

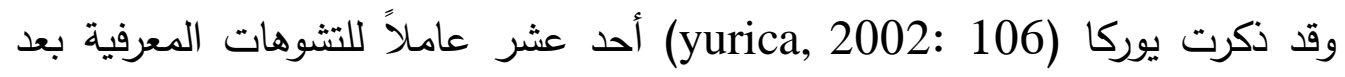
التحليل العاملي للعديد من النظريات وهي كما يلي: التقييم الخارجي للذات ( Externalization) of self-Worth

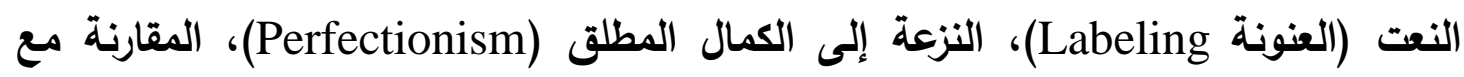

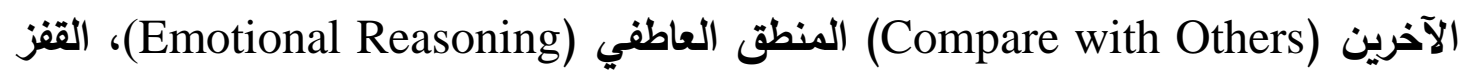

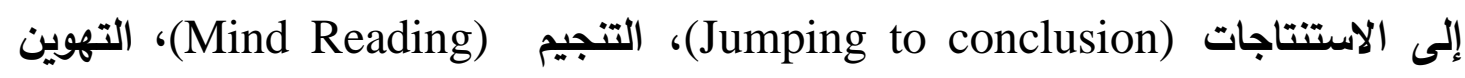
.). (Emotional reasoning) (الاستدلال العاطفي (Minimization)

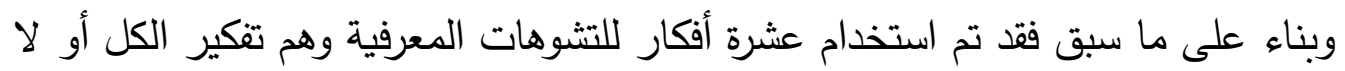
شيئ، الثخصنة واللوم، التنكير الكارثي، الينبغيات، التجريد الانتقائي، التعديم الذائد، التهويل

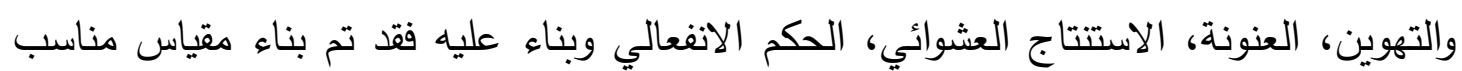
للأبعاد ولمرحلة الثانوية العامة وفيما يلي تعريف الباحثة لهذه الأبعاد. تفكير (الكل أو لاشيئ) المستقطب (All or nothing thinking): وهو الحكم الطرفي حيث يرى الفرد الأحداث إما أبيض أو أسود لا يووجد وسط. 
الشخصنة أو اللوم (personalization and blam): وتعني تحمل المسؤلية الشخصية عن الأحداث السلبية التي تمر ، وتفسيرها بشكل شخصي، وكثرة لوم نفسه.

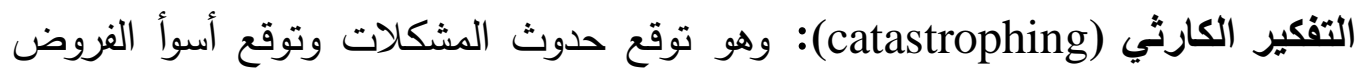

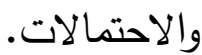

الينبغيات أو الحتميات (should or must statements): وهي رؤية ما ينبغي الوصول إليه دون النظر إلى الامكانيات فيرى نفسه دائمًا مقصرًا دومًا إذا لم يصل إلى ما ينشده. التجريد الانتقائي أو التصفية العقلية (mental filter): وهي انتقاء بعض أجزاء الموقف

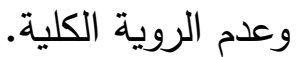
الذائد(overgeneralization): تعميم أي موقف وفقًا لوجهة نظره وخلفيته

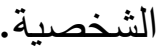
التهويل أو التهوين (magnification\& minimization): أن يضخم الموقف فيراه أكبر مما هو عليه أو العكس. العنونة (labeling): إضفاء العناوين السلبية على نفسه أو الأحداث. الاستنتاج العشوائي (Jumping to conclusion): أن يستنتج الفرد استنتاجات سلبية دون التحقق من صحتها أو بتبني أدلة غير واقعية. الحكم الانفعالي (emotional reasoning):أن يفهم أو يحكم الفرد أو يتخذ القرارات وفقًا

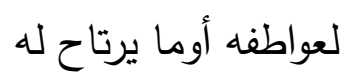

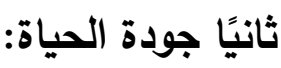

لقد ظهر مصطلح جودة الحياة ضمن علم النفس الإيجابي والذي دخل الحقل الأكاديمي لعلم النفس عام (99191) عندما دعا "مارتين سيلجمان" (seligman, 2000) علماء النفس للبحث عن القوى الإيجابية والعوامل الثخصية لاى البشر، والتي تجعل الحياة جديرة أن تعاش كبديل للجوانب السلبية والاضطرابات الشخصية، ويشير "سيلجمان" أن علم النفس الإيجابي اهتم بتحسين وزيادة رضا الفرد عن حياته، وتجويد نوعية حياته في مختلف مواقف الحياة (فوزية علي داهم، . (ro: 10

وتوجد مجموعة من التعريفات التي استخدت للتعبير عن جودة الحياة نذكر منها ما يلي: ويعرف "ثالوك" جودة الحياة (Schalock, 2000: 121) أنها مفهوم يعكس ويوضح الظروف

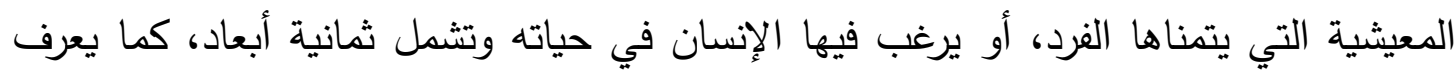

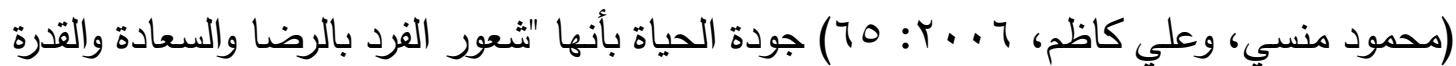
علي إثباع حاجاته من خلال ثراء البيئة ورقي الخدمات التي تقدم له في الدجالات الصحية، 
والاجتماعية، والتعليمية، والنفسية، مع حسن إدارته للوقت والاستفادة منه ويوضح هذا المفهوم نوعية الحياه التي يرغب الإنسان أن يحققها". ويضع أودسي وآخرون (Odac1, et al., 2009:57) تعريفًا مبسطًا لجودة الحياة بأنها

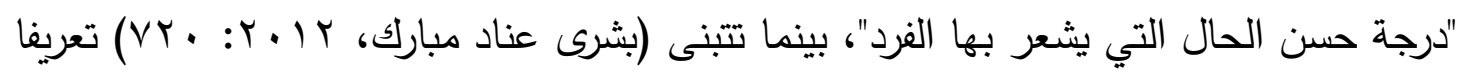

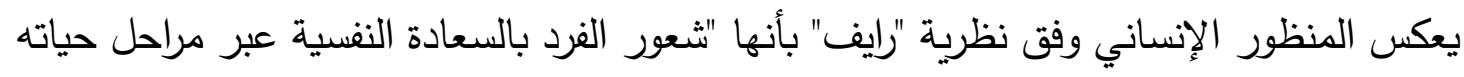

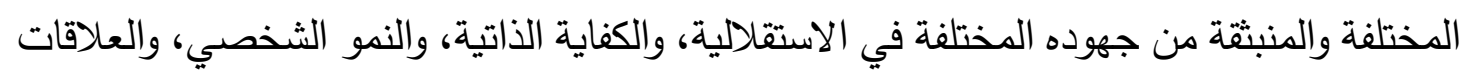
الإيجابية مع الآخرين، وتقبل الذات، لتحقيق أهدافه في الحياة".

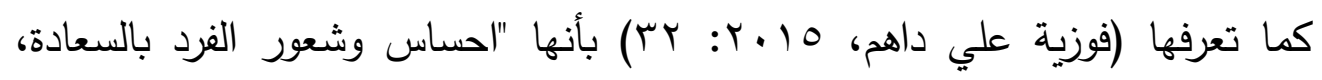
والرضا، والرفاهية التي تظهر في التعليم والدراسة، والصحة النفسية، وفي شغل الوقت و و إدارته،

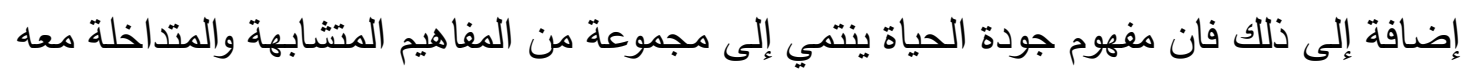

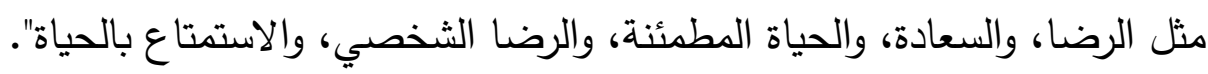

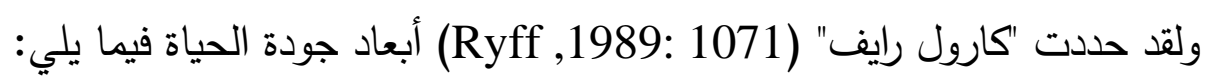
أ- - تقبل الذات (Self-acceptance): ويثير إلى "القدرة على أقصى مدى تسمح به القدرات والإمكانيات، والنضج الشخصي، والاتجاه الايجابي نحو الذات.

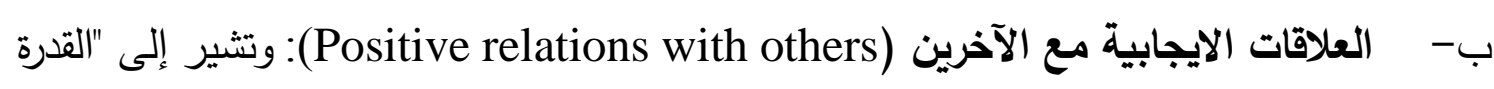
على إقامة علاقات اجتماعية ايجابية مع الآخرين قائمة على التثة والقدرة على التفاعل مع الإنع الآخرين، والقدرة على الأخذ والعطاء.

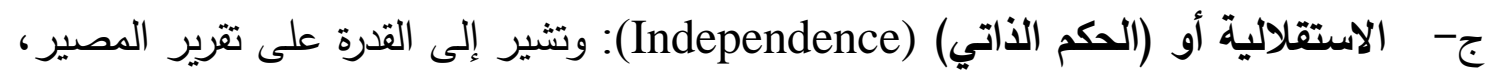

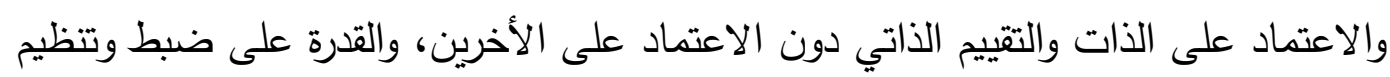

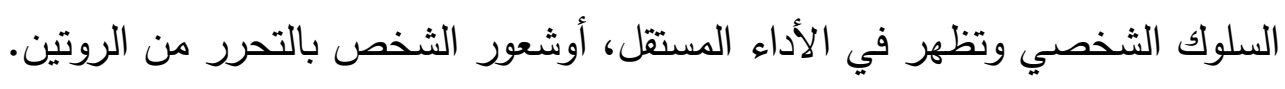

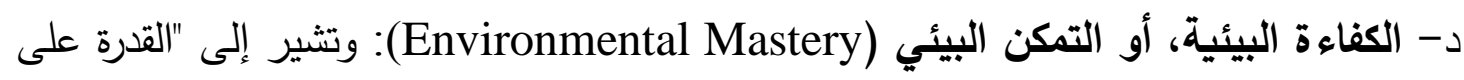

اختيار وتخيل البيئات المناسبة، والمرونة الثخصية أثناء التواجد في السياقات البيئية". هـ - هدفية الحياة (Purpose in life): وتشير إلى "أن يكون للفرد هدف في الحياة، ورؤية وتوجه في تصرفاته وأفعاله نحو تحقيق هذا الهدف، ومثابرة مثل أن يكون الفرد منتجًا ومبدعًا". و - النمو الثخصي (Personal growth): وتثير إلى تطوير الإمكانات، إدراك الفرد الواقعي لهي للحياة وشعوره بالنمو وانفتاحه على التجارب الجديدة وترتبط بسمات الشخصية في الانفتاح على الخبرة لمواجهة التحديات الجديدة في فترات مختلفة من الحياة".

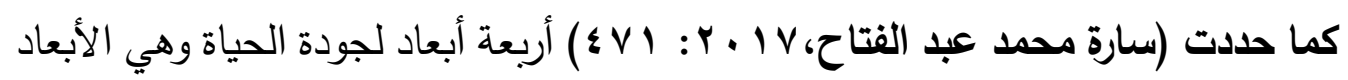

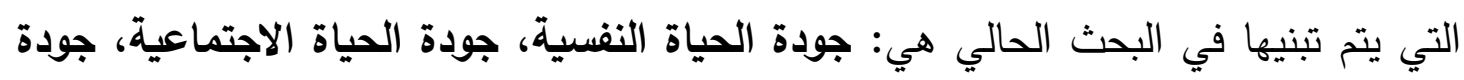
الحياة الأكاديمية، جودة الحياة الجسمية. 


\section{(1) - (البحوث السابقة}

\section{المحور الأول: بحوث تناولت العلاقة بين التشوهات المعرفية وجودة الحياة.}

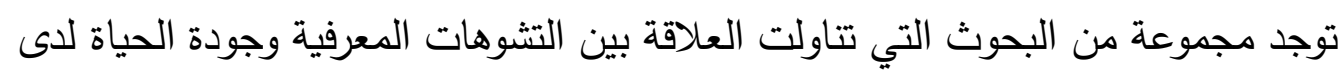

عينات متنوعة حيث يتناول بحث (Odacl, et al., 2009) التشوهات المعرفية كمؤشر لجودة

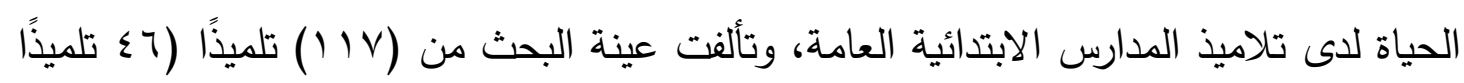

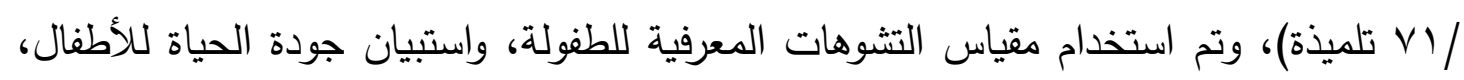

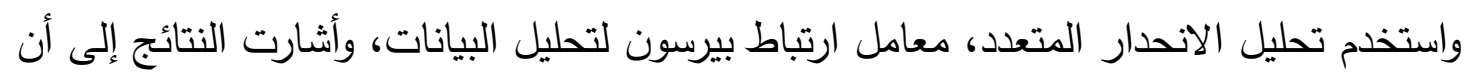

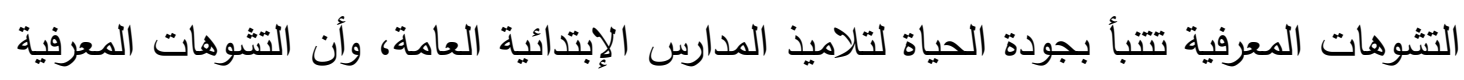
ذات علاقة ارتباطية سالبة دالة إحصائيا عند ( ال,.•) بجودة الحياة لدى تلاميذ المرحلة الإبتدائية

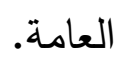

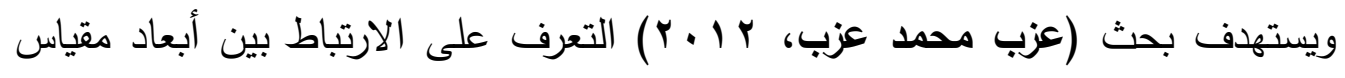

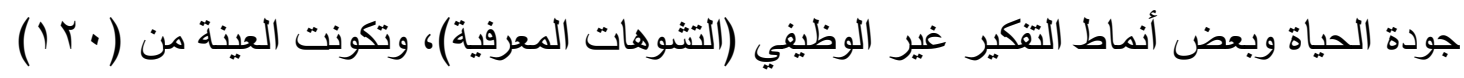

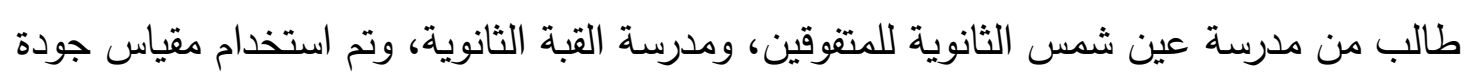

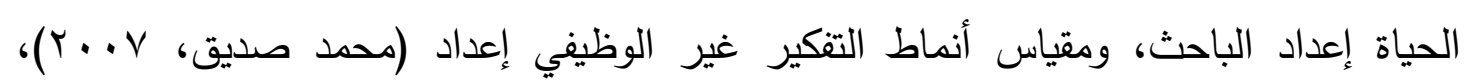

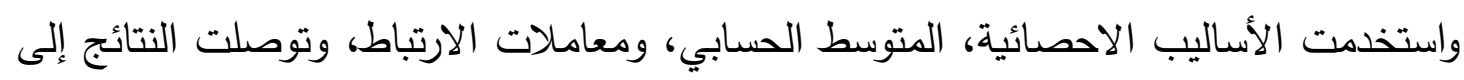

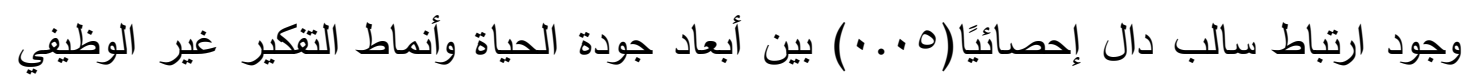

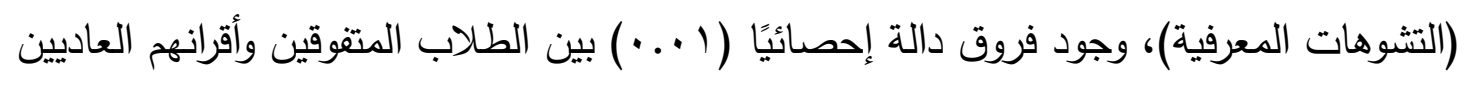
في أبعاد جودة الحياة لصالح المتفوقين. كما يركز بحث (Çelik \& Odac, 2013) العلاقة بين اشكالية استخدام الانترنت وكل من التشوهات المعرفية، والرضا عن الحياة كأحد أبعاد جودة الحياة للى طلبة الجامعة في ماليزيا.

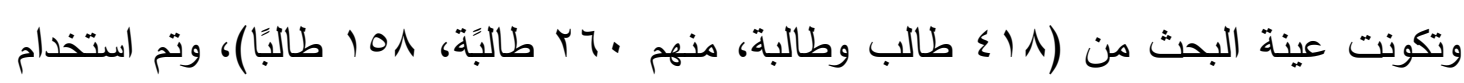

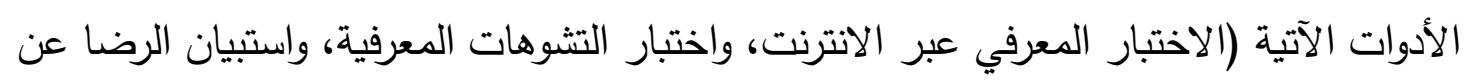

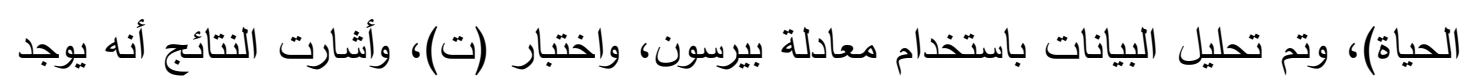

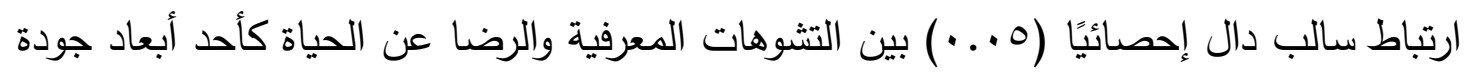

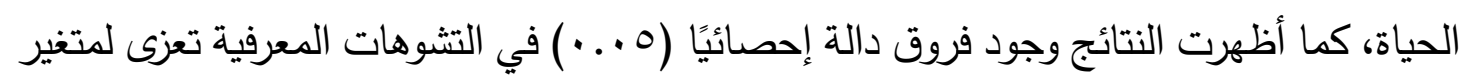

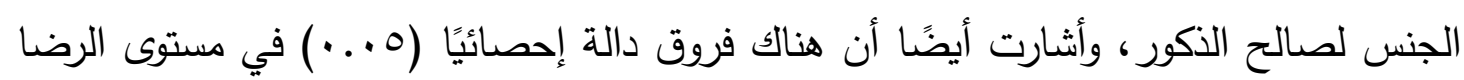
عن الحياة كأحد أبعاد جودة الحياة ولصالح الإناث. 
ويختبر بحث (Besta et al., 2014) موثوقية وصحة النسخة البولندية من مقياس

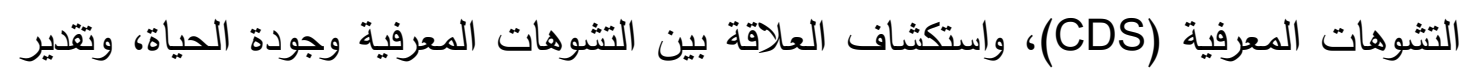
وتوكيد الذات، ومستوى القلق. وأجريت دراستين متلازمتين لاى طلاب علم النفس، وتكونت العينة

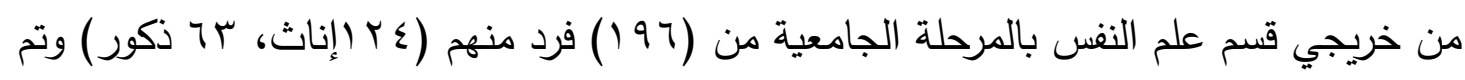
تطبيق (استبيان الأخطاء المعرفية المترجم (Covin, et al , 2011)، واختبار القلق كسمة وكحالة لسبيلبيرج وأخرون (Ppielberg et al., 1983)، واختبار جودة الحياة (Pavot \& Diener)

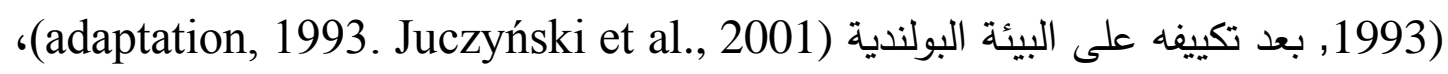

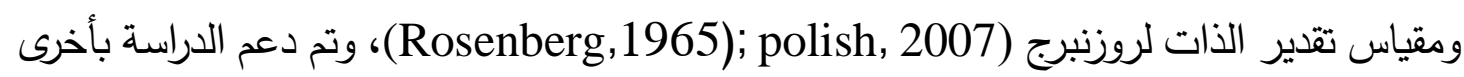

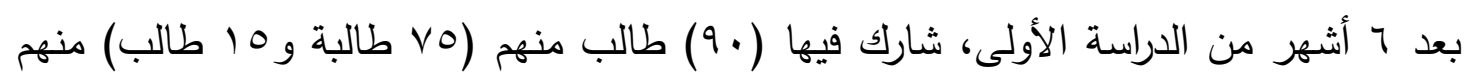
(§V) شاركوا في الدراسة الأولى، وتم فيها تحليل العلاقة بين اختبار التشوهات المعرفية، والقلق (كسمة، وكحالة)، وجودة الحياة، وجود ارتباطات سالبة للتشوهات المعرفية, والجودة المدركة للحياة. كما يبين بحث (Garruba, 2015) دور التشوهات المعرفية في التكيف مع الإعاقة والجودة الددركة للحياة لدى الأفراد، ويتعرف على مستوى التشوهات المعرفية لاى أفراد العينة. وتكونت العينة من (1/1) فرد من الناجين من إصابات النخاع الشوكي الاسبان، وباستخدام

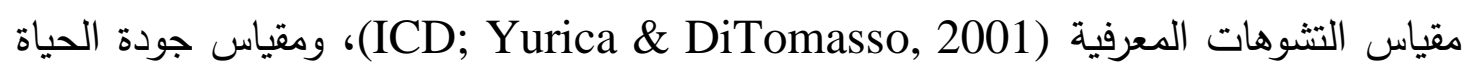
(WHOQOL Group, 1998)، وباستخدام التحليلات الإحصائية المتوسطات، والانحرافات المعيارية، وتحليل التباين الثنائي، تم التوصل إلى وجود ارتباط سالب دال إحصائيًا عند (0. . . )

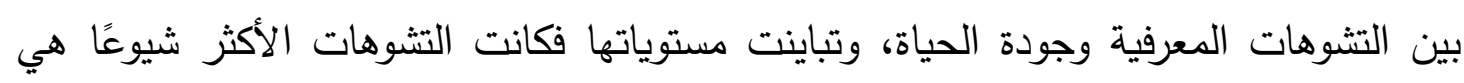
بالترتيب التفكير الانفعالي، الكمالية، الحكم الانفعالي، وأقلها التهويل والتهوين، إضفاء واتئه العناوين، الاستدلال التعنفي. المحور الثاني: بحوث تناولت تأثير بعض المتغيرات الايموغرافية (النوع، التخصص الدراسي) على متغيرات البحث. توجد مجموعة من البحوث التي تتاولت تأثير بعض المتغيرات الديموغرافية على متغيرات البحث ومنها بحث برونو (2010, Bruno) الذي يهدف إلى معرفة العلاقة بين التشوهات المعرفية

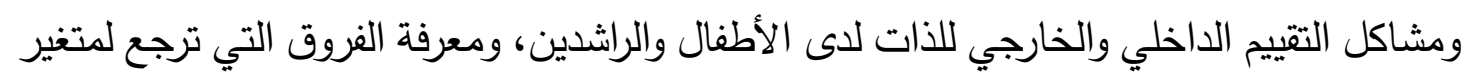

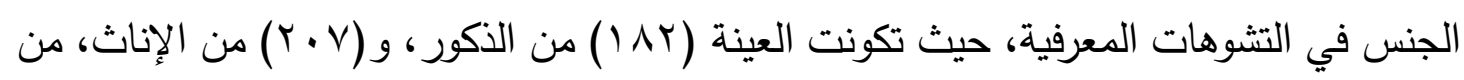

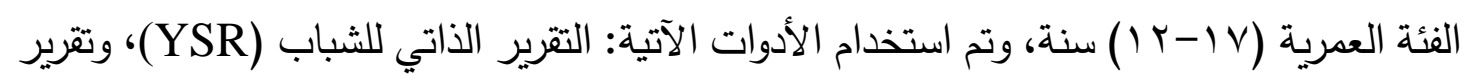

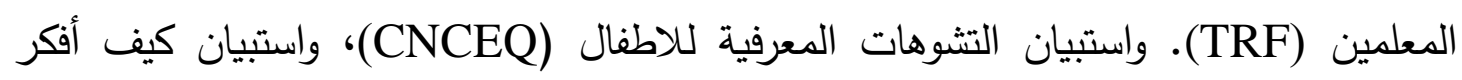
للتشوهات المعرفية الخادمة للذات (HITQ)، وباستخدام الأسلوب الاحصائي في سلسلة تحليل 
الانحدار الهرمي بينت النتائج أنه لا توجد فروق ذات دلالة إحصائية ترجع لمتغير الجنس في كل من التشوهات المعرفية.

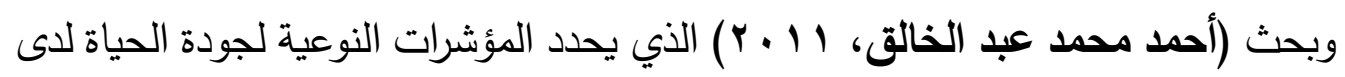
عينة من طلاب المدارس الثانوية للكويتيين، ويبحث الفروق بين الجنسين والمقارنة بالنتائج السابقة

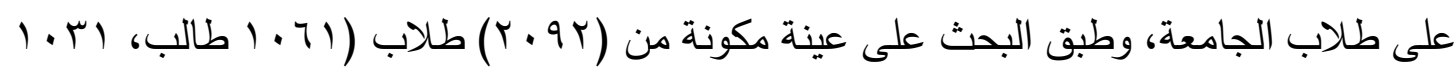
طالبة) تراوحت أعمارهم بين (10، 9 (1) سنة، واستخدمت الصيغة العربية لمقياس جودة الحئة الحياة المختصر الصادر عن منظمة الصحة العالمية و991ام، وتم استخدام المتوسطات والانحرافات المعيارية، وحصل الذكور على متوسطات أعلى من الإناث في جودة الحياة بمستوى دال في

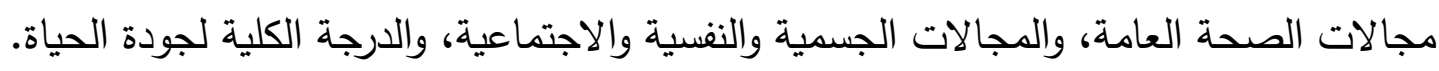

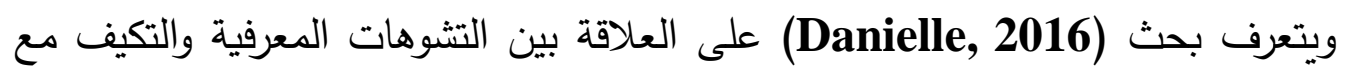
الإعاقة، وجودة الحياة، ومتغيرات الجنس والعمر للى الراشدين ذوي عجز الانتباه، وتكونت العينة

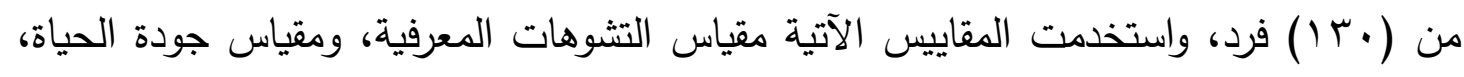

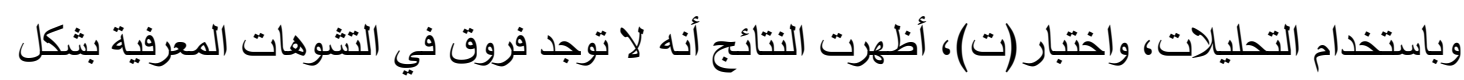

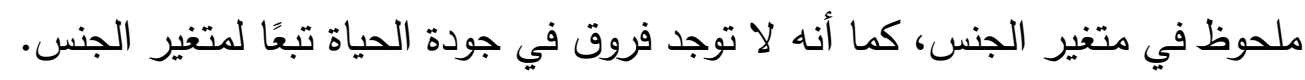

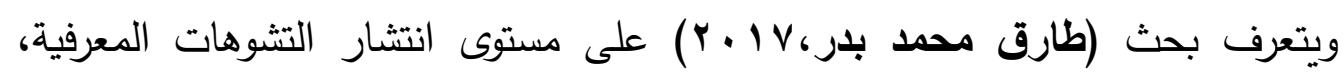

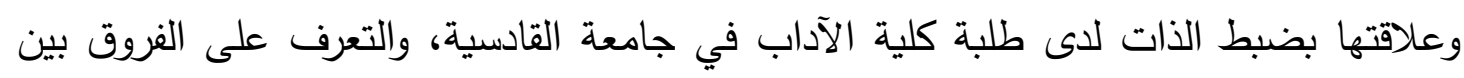

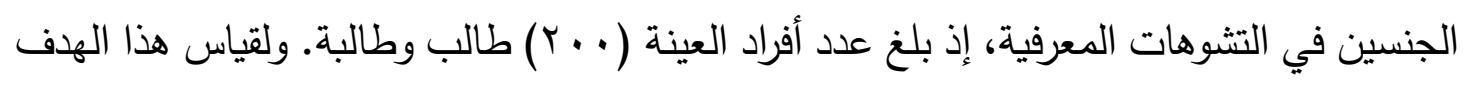

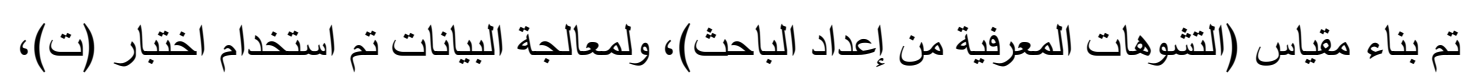

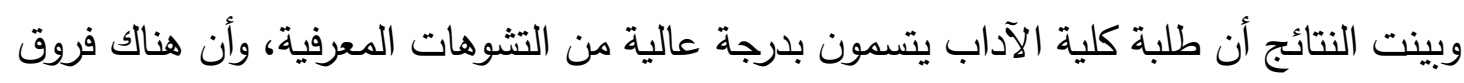
ذات دلالة إحصائية للتشوهات المعرفية وفق متغير النوع ولصالح الذكور حيث كانوا أكثر تشوهًا

معرفيًا.

بينما يستكثف بحث (عيسى إبراهيم تواني، Y IV) العلاقة بين المخططات المبكرة غير المتكيفة والتشوهات المعرفية، وبحث الفروق في التشوهات المعرفية تبعا لمتغير الجنس، واستخدم الباحث مقياس المخططات المبكرة غير المتكيفة ليونج، واستبيان التشوهات المعرفية لدى أوليفيرا،

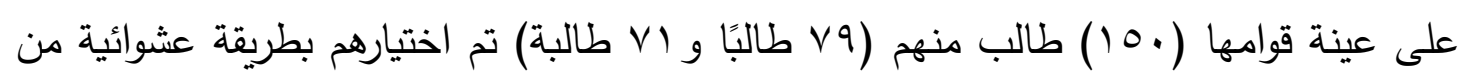

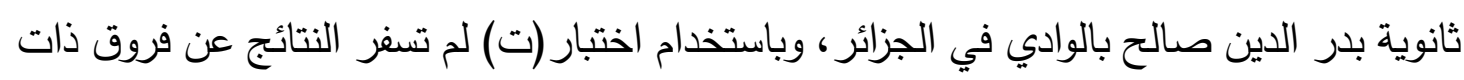

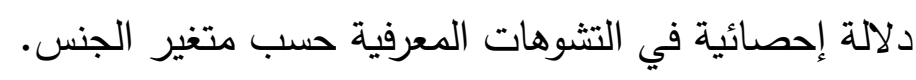

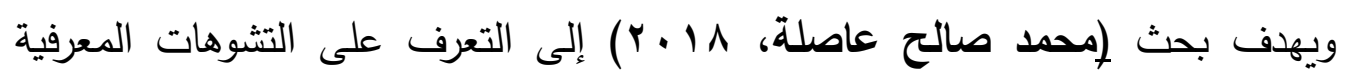

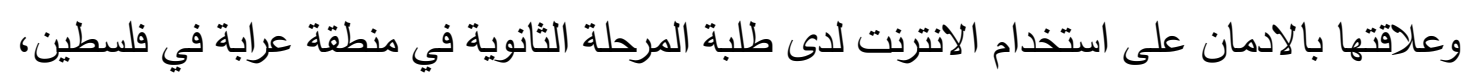

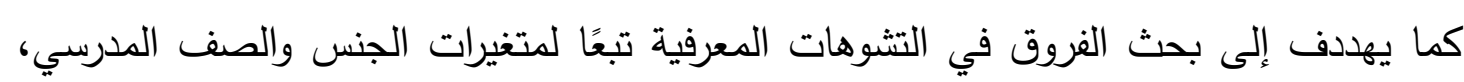


وتكونت عينة الدراسة من (Y \&V) طالبًا وطالبة، وتم استخدام الأدوات التالية (مقياس التشوهات المعرفية المعد من قبل كوفينو (Covino, 2013) تعريب الباحث، ومقياس الادمان على استخدام الانترنت إعداد كيسير وآخرون (2013, Keser,et.al)، وباستخدام اختبار (ت) كما أظهرت النتائج أنه لا توجد فروق دالة إحصائيًا في مستوى التشوهات المعرفية لدى الطلبة تعزى لـتغيري الجنس، والصف المدرسي.

\section{تعليق على البحوث السابقة:}

تناولت البحوث السابقة المنهج الوصفي كما تباينت في استخدامها للأدوات، منهم من

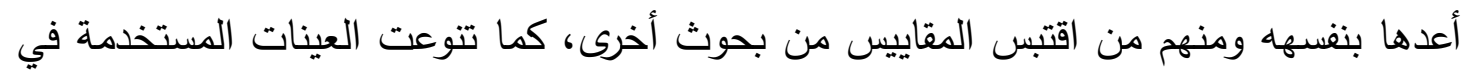

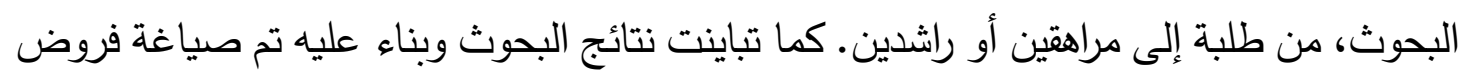
البحث كما يلي:

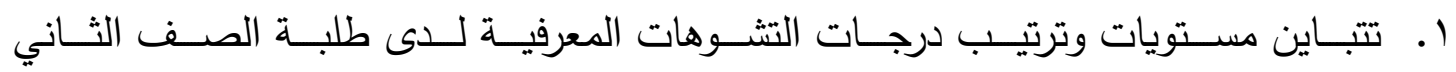
الثانوي العام.

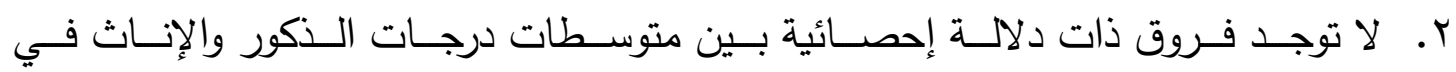
مقياس التشوهات لدى طلبة الصف الثاني الثانوي العام. r. لا توجد فروق ذات دلالة إحصائية بين متوسطات درجات طلاب التخصصات العلمية،

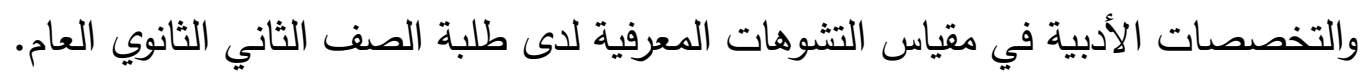
ع. يوجد ارتباط سلبي دال إحصائيًا عند مستوى (0...) بين درجات التشوهات المعرفية ودرجات جودة الحياة.

\section{إجراءات البحث: أولًا منهج البحث: ودأه}

لقد تم استخدام (المنهج الوصفي) ويعتمد على دراسة الظاهرة واقعيًا، ثم تطبيق النتائج، والتوصل إلى تعميمات. ثانيًا مجتمع البحث:

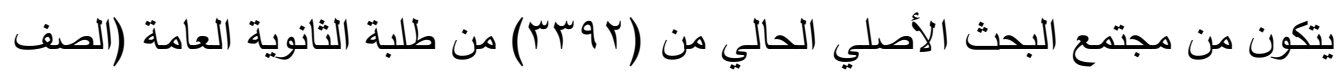

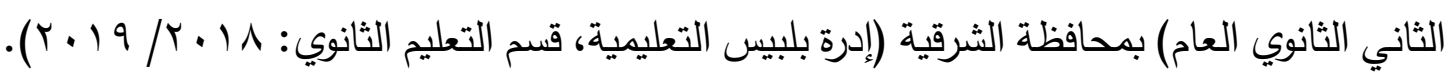

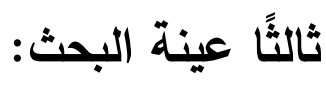

تم اشتقاق عينة البحث الحالي بطريقة عشوائية من طلبة الصف الثاني الثانوي العام بإدارة بلبيس التعليمية بمحافظة الثرقية، وتم اختيار عينة من المرحلة الثانوية ذلك لأن: تتركز أغلبية 
البحوث السابقة على طلبة الجامعة وعينات من الراشدين والقليل منها على المرحلة الثانوية، مما دعى الباحثة إلى التعقى في معرفة خصائص طلبة تللك المرحلة، كما تعتبر المرحلة الثانوية ولثية المرحلة الفاصلة بين الطفولة والنضج والتي تتثكل فيها شخصيته، وتكتمل فيها طريقته الخاصة في مواجهة تحديات المستقبل.

أ) عينة حساب الخصائص السيكومترية: تكونت عينة حساب الخصائص السيكومترية من ( • (7) طالبًا وطالبةً من الصف الثاني الثانوي العام بإدارة بلبيس التعليمية بمحافظة الثرقية، للتحقق من (الصدق، والثبات، والاتساق

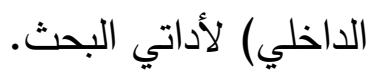

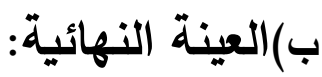

تكونت عينة البحث النهائية من (ro.ro طالبًا وطالبة من طلبة الصف الثاني الثانوي

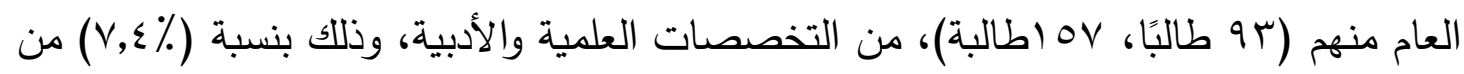

$$
\text { الرجعًا: أدوات البحث الأصلي. }
$$

تم إعداد مقياس التشوهات المعرفية لقياس التشوهات المعرفية لدى طلبة الثانوية العامة

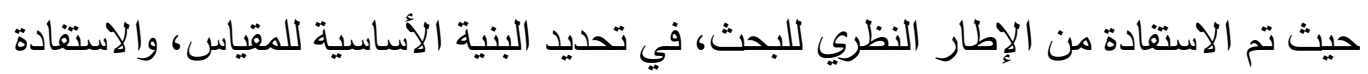

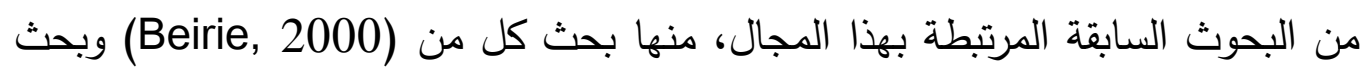

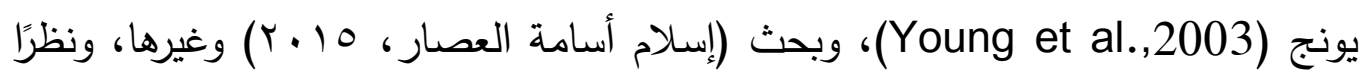

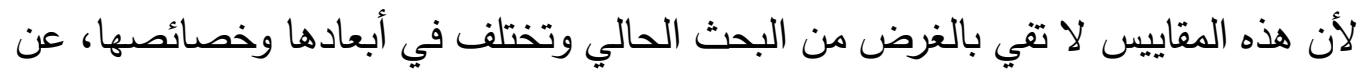

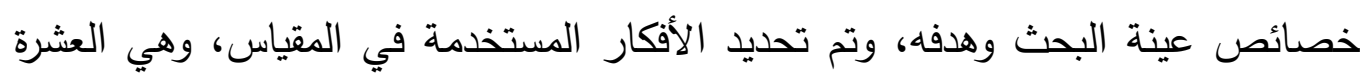

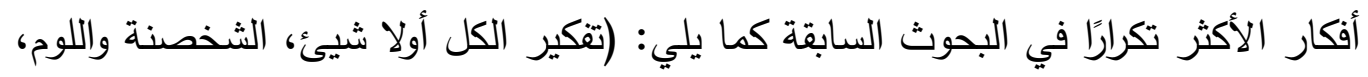

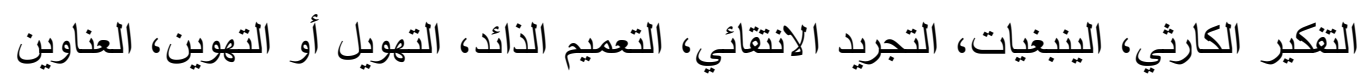

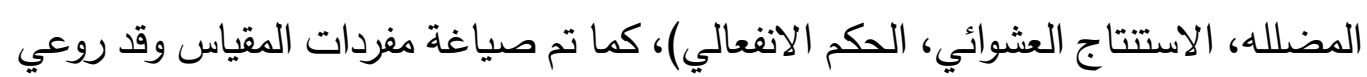

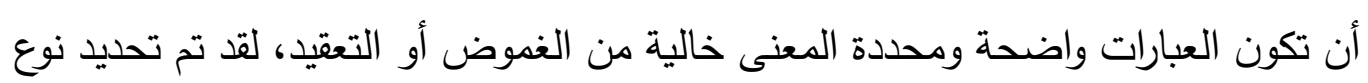

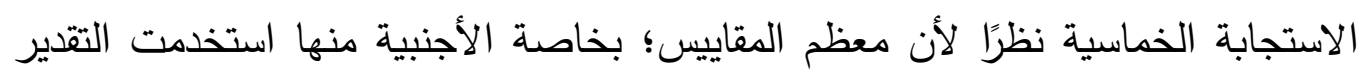

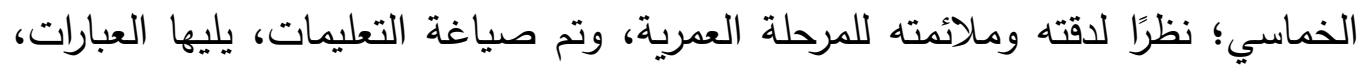

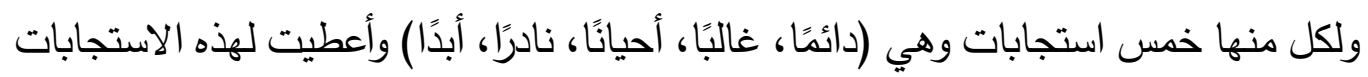

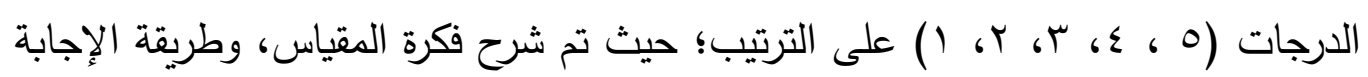


عليه في ورقة الإجابة التي يكتب فيها الطالب بياناته من حيث (الاسم "اختياري"، التخصص،

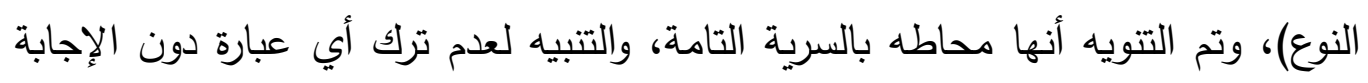
عليها، ومراعاة إكمال البيانات الثخصية بدقة.

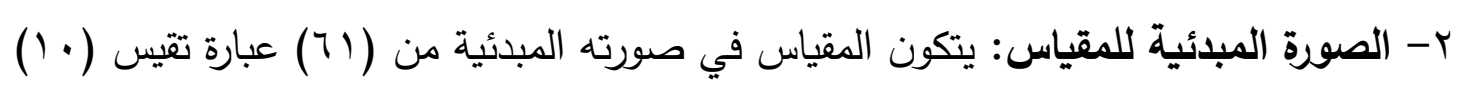

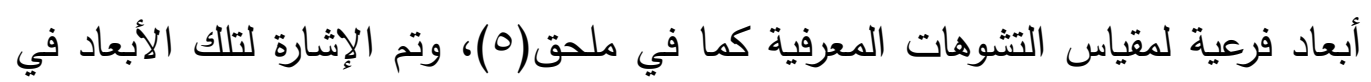
فصل الإطار النظري.

\section{ب-العرض على المحكمين (صدق المحكمين):}

تم عرض الصورة المبدئية للمقياس على ثمانية محكمين من أعضاء هيئة التدريس بقسم علم

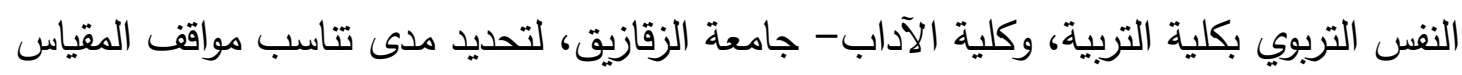

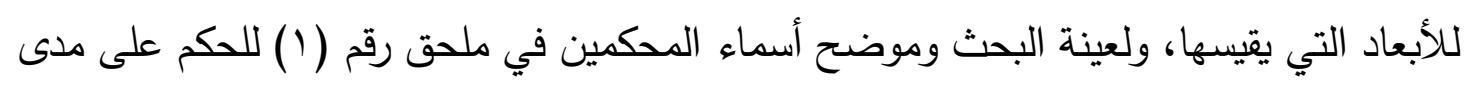

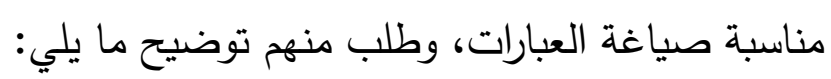
مدى انتماء عبارات المقياس لتعريف كل بعد من أبعاده، تحديد ما إذا كانت العبارة موجبة توضية أم سالبة، وإضافة أي ملاحظة يرونها مناسبة، وقد تم الاستفادة من آراء المحكمين في تعديل

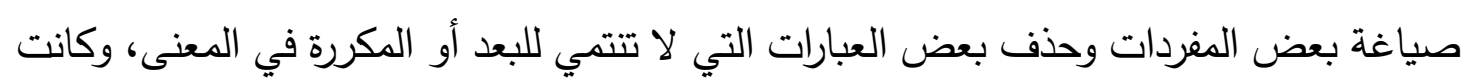

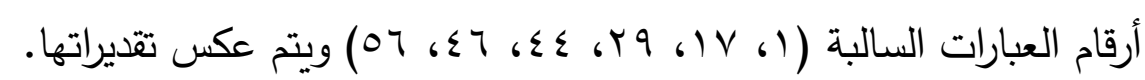
ع - التطبيق المبلئي للمقياس:

تم تطبيق المقياس بعد عرضه على ثمانية من المحكمين من الأساتذة في علم النفس النس

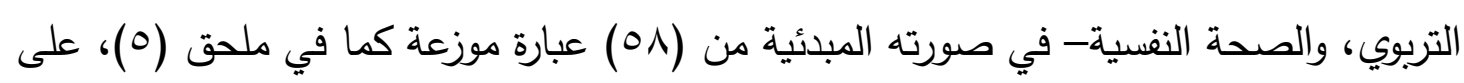

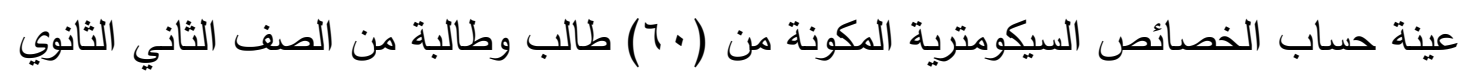

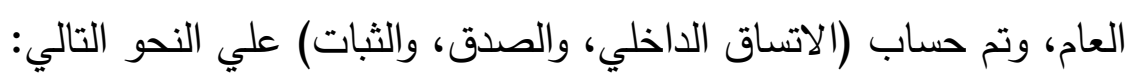
الاتساق الااخلي: تم حساب معاملات الارتباط بين درجات العبارات والدرجات الكلية الاتلية

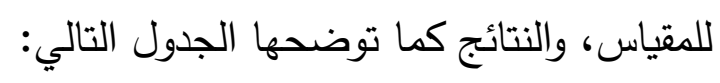

جدول (r) معاملات الارتباط لمقياس التشوهات المعرفية (ن = • ؟ )

\begin{tabular}{|c|c|c|c|c|c|c|c|}
\hline معامل الارتباط & الرقم & معامل الارتباط & الرقم & معامل الارتباط & الرقم & معامل الارتباط & الرقم \\
\hline *., Y & $\leq 4$ & * & $\mu_{1}$ & $* .$, r q V & 17 &., $1 v_{0}$ & 1 \\
\hline 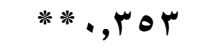 & $\leqslant v$ & ***, & rr & § & iv & 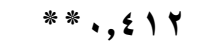 & r \\
\hline Vד & $\varepsilon \wedge$ & ***,,$\Gamma \wedge \wedge$ & $r r$ & 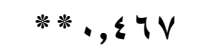 & 11 & $* *, 011$ & $r$ \\
\hline
\end{tabular}




\begin{tabular}{|c|c|c|c|c|c|c|c|}
\hline$* *,, \varepsilon \cdot \Lambda$ & $\leq 9$ & $* *, r, r q$ & r &., .01 & 19 & $*,, r \cdot q$ & $\varepsilon$ \\
\hline **, , , $\{r \mid$ & 0. & $* *, r \wedge q$ & ro & $* *, r \wedge q$ & $r$. & **, & 0 \\
\hline$* *,, \leq \wedge \leq$ & 01 & $*,, r q \wedge$ & q &.,$I V Y$ & Y & $* *, r \vee \neg$ & 9 \\
\hline$* *, \diamond ৭ \wedge$ & or & $* *$, , $\leqslant \vee \nearrow$ & rv & $*,, r q q$ & $r r$ & $*, r \wedge \wedge$ & v \\
\hline 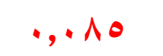 & or & **, & $\mu \wedge$ & 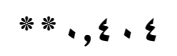 & $r r$ & ג & $\wedge$ \\
\hline$* *,, r \wedge q$ & $0 \leq$ & $* *,, r \leqslant r$ & $r q$ & $*, \mu \mid V$ & $r \varepsilon$ & $*, r q \wedge$ & 9 \\
\hline$* *, r r q$ & 00 & $*$ *, Үq & $\varepsilon$. & $* *$, , $\{\diamond \diamond$ & ro & $* *, r \leq V$ & 1. \\
\hline$*$ *, rq & 07 & r & $\leqslant 1$ & $*, \mu l \leq$ & rq & । & 11 \\
\hline ., & ov & **, * & $\varepsilon r$ & *, , & rV & . & Ir \\
\hline$* *, r \wedge I$ & $\Delta \wedge$ & $* *, \diamond \wedge \wedge$ & $\varepsilon r$ & ***, • & r^ & ** & Ir \\
\hline & & **, , , $\{Y$ & $\varepsilon \varepsilon$ & . & rq & $* *,, \leq 1 \leq$ & $1 \varepsilon$ \\
\hline & & * , , r r r & $\leq 0$ & $* * ., £ 19$ & $\mu$. & $* *$, * $\{\curlyvee \wedge$ & 10 \\
\hline
\end{tabular}

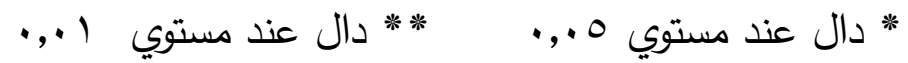

يتضح من الجدول أن جميع معاملات الارتباط دالة إحصائيًا, عدا (9) عبارات, وأرقامها:

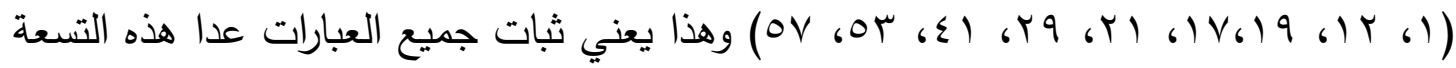

فهي غير ثابته.

ثبات الأبعاد: بعد حذف العبارات غير الثابتة تم حساب معاملات الارتباط للمقياس كما في الجدول

جدول (•) معاملات الارتباط بين درجات الأبعاد والدرجة الكلية لمقياس التشوهات

المعرفية (ن= • 7 طالب)

\begin{tabular}{|c|c|c|}
\hline معامل الارتباط مع الدرجة الكلية & أبعاد مقياس التشوهات المعرفية & م \\
\hline$* *, 0 \leq$ & تفكير الكل أو لا شيء & 1 \\
\hline$* *,, \neg \wedge \varepsilon$ & الشخصنة واللوم & $r$ \\
\hline$* *, 791$ & التفكير الكارثي & $\mu$ \\
\hline
\end{tabular}




\begin{tabular}{|c|c|c|}
\hline$* *, r \mu q$ & الينبغيات & $\varepsilon$ \\
\hline ***, , ฯ ४ & التجريد الانتقائي & 0 \\
\hline$* *,, \vee \bullet \wedge$ & التعميم الزائد & 7 \\
\hline$* *,, 7 \leqslant V$ & التهويل أو التهوين & v \\
\hline$* *,, \vee r q$ & إضفاء العناوين & $\Lambda$ \\
\hline$* *, 7,9$ & الاستتناج العشوائي & 9 \\
\hline$* *, r \in \varepsilon V$ & الحكم الانفعالي & 1. \\
\hline
\end{tabular}

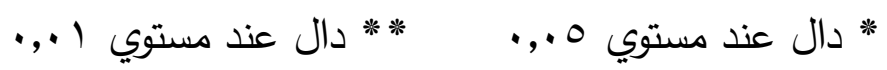

يتضح من الجدول أن جميع قيم معاملات الارتباط دالة إحصائيًا, مما يدل علي ثبات

$$
\text { جميع الأبعاد. }
$$

صدق المقياس: لقد تبين صدق جميع العبارات عدا تسع عبارات غير صادقة, ومن الإجراءات

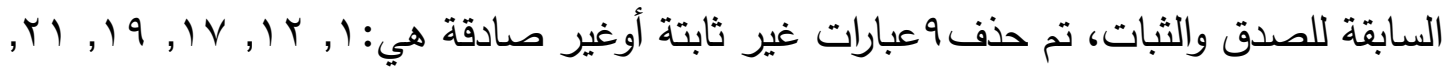

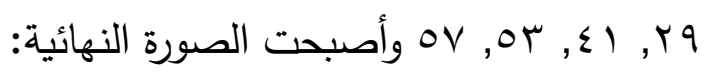

\begin{tabular}{|c|c|c|c|}
\hline أرقام المفردات & عدد العبارات & اسم البعد & م \\
\hline$\varepsilon \Lambda-\varepsilon \varepsilon-r \Lambda-r 1-r r-10$ & 7 & تفكير الكل أولا شيئ & 1 \\
\hline$\leqslant 0-r r-q-1$ & $\varepsilon$ & الشخصنة واللوم & r \\
\hline$r \leqslant-17-1 \cdot-r$ & $\varepsilon$ & التفكير الكارثي & $\mu$ \\
\hline$r q-r r-r \theta-r$ & $\varepsilon$ & الينبغيات & $\varepsilon$ \\
\hline$\varepsilon \cdot-r \varepsilon-r q-1 V-11$ & - & التجريد الانتقائي & 0 \\
\hline $\begin{array}{r}-\varepsilon q-\varepsilon 1-r V-11-1 Y-\varepsilon \\
-\varepsilon q\end{array}$ & v & التعميم الذائد & 9 \\
\hline
\end{tabular}

جدول (V) عدد عبارات أبعاد مقياس التشوهات المعرفية في الصورة النهائية. 


\begin{tabular}{|c|c|c|c|}
\hline $\begin{array}{r}-\varepsilon-r \Delta-r \cdot-r \wedge-19-0 \\
\leqslant V\end{array}$ & V & التهويل أو التهوين & $v$ \\
\hline$r q-r q-r \cdot-1 r-q$ & $\bullet$ & العناوين المضللة & $\Lambda$ \\
\hline$\leqslant r-Y 1-1 \leqslant-V$ & $\varepsilon$ & الاستتتاج العشوائي & 9 \\
\hline \multirow[t]{2}{*}{$r V-r r-\Lambda$} & $\mu$ & الحكم الانفعالي & 1. \\
\hline & $\leqslant 9$ & \multicolumn{2}{|l|}{ المجموع } \\
\hline
\end{tabular}

\section{ثانيًا: مقياس جودة الحياة إعداد (سارة محمد عبد الفتاح، IV) . Y).}

الهرف من المقياس:

أعد هذا المقياس (سارة محمد عبد الفتاح، 7 ( • ب) بهدف قياس جودة الحياة ويتكون من

أربعة أبعاد، وهي نوعًا من التقرير الذاتي يجيب عنها الأفراد في ضوء تدرج ثلاثي الاستجابة

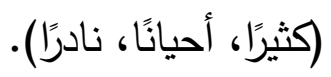

وصف المقياس: يتكون المقياس من (₹V) عبارة في صورته الأصلية موزعة على أربعة أبعاد كما يلي:

جدول (T I) توزيع مفردات مقياس جودة الحياة على الأبعاد وعددها.

\begin{tabular}{|c|c|c|}
\hline عدد المفردات & أرقام المفردات & البعد \\
\hline ir & 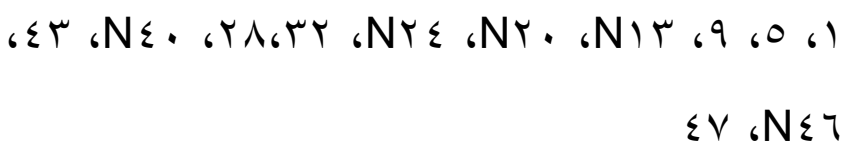 & جودة الحياة النفسية \\
\hline 1. & r & جودة الحياة الاجتماعية \\
\hline
\end{tabular}




\begin{tabular}{|c|c|c|}
\hline 11 & 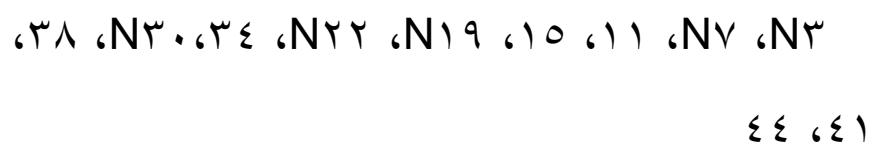 & جودة الحياة الأكاديمية \\
\hline $1 \varepsilon$ & 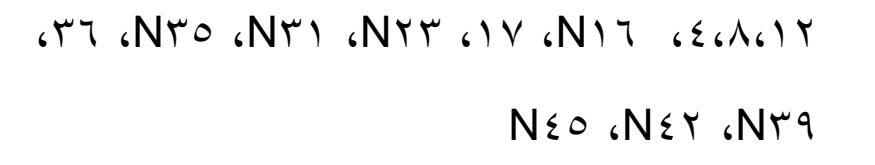 & جودة الحياة الجسمية \\
\hline$\leq v$ & مجموع مفردات جودة الحياة & \\
\hline
\end{tabular}

يرمز للمفردات السالبة بالرمز N التي يعكس تقدير الدرجات لها على استجابة ثلاثية

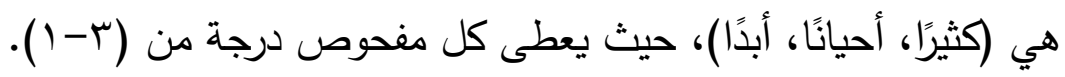

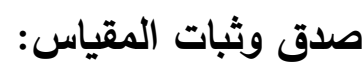

أولاً: الصدق: تم إيجاد صدق المقياس بأكثر من طريقة منها صدق المحكمين، الصدق

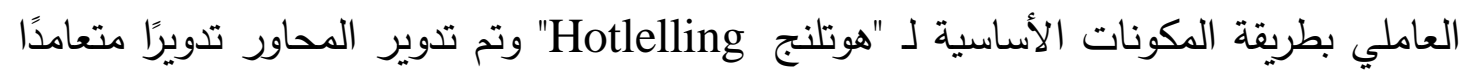
بطريقة الفاريماكس Varimax، كما تم حساب الصدق التمييزي، وتبين وجود فروق واضحة دالة لثينة إحصائيًا. ثانَيا ثبات المقياس:

قامت معدة المقياس بحساب ثبات بطريقة التجزئة النصفية وذللك لكل بعد وكانت

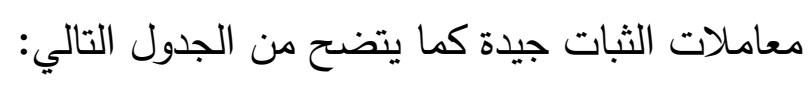

\begin{tabular}{|c|c|}
\hline معامل الثبات بطريقة التجزئة النصفية & الأبعاد \\
\hline •, & جودة الحياة النفسية \\
\hline$\cdot, \vee \vee$. & جودة الحياة الاجتماعية \\
\hline$\cdot, \leqslant \vee q$ & جودة الحياة الأكاديمية \\
\hline , $4 \wedge 0$ & جودة الحياة الجسمية \\
\hline., $9 \cdot 9$ & الارجة الكلية \\
\hline
\end{tabular}

جدول (ء ا ) ثبات مقياس جودة العياة بطريقة التجزئة النصفية.

يتضح من الجدول السابق أن قيم معاملات الثبات بطريقة التجزئة النصفية مما يبين

ثبات المقياس وصدقه، مما يجعله صالح للاستخدام. حساب الخصائص السيكوترية للمقياس (الاتساق، والصدق، ولثة والثبات) على عينة البحث الحالي. 
تم تطبيق المقياس علي العينة المبدئية, المكونة من (• ج) طالبًا وطالبةً بالصف الثاني

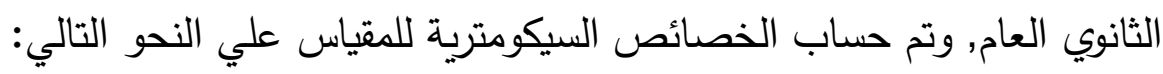

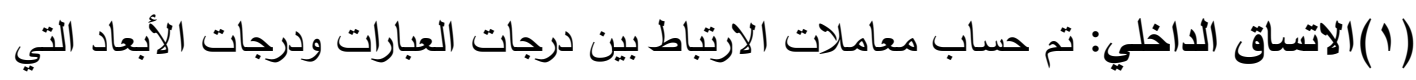

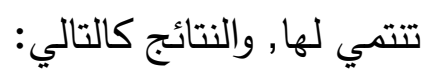
جدول (0 1) معاملات الارتباط بين درجات عبارات مقياس جودة الحياة ودرجات الأبعاد الفرعية للمقياس.

\begin{tabular}{|c|c|c|c|c|c|c|c|}
\hline \multicolumn{2}{|c|}{ جودة الحياة الجسمية } & \multicolumn{2}{|c|}{ جودة الحياة الأكاديمية } & \multicolumn{2}{|c|}{ جودة الحياة الاجتماعية } & \multicolumn{2}{|c|}{ جودة الحياة النفسية } \\
\hline معامل الارتباط & 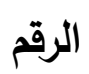 & معامل الارتباط & 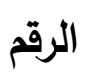 & معامل الارتباط & 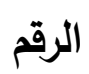 & معامل الارتباط & 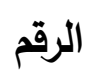 \\
\hline$* *,, O Y \varepsilon$ & $\varepsilon$ & $* *,, \vee \bullet$. & $\mu$ & $* *,, \leqslant 0$. & r & $* *,, 0 \wedge \uparrow$ & 1 \\
\hline$* *, \mu \Delta \Delta$ & $\wedge$ & $\cdot, \cdot, \leqslant 7$ & $v$ & $* *$, * $\{$ Y & 7 & $* *, r \wedge q$ & ○ \\
\hline$* *, r \wedge \vee$ & ir & $* *$, , rVo & 11 & $* *, v, r$ & 1 & $* *,\{\ldots$ & 9 \\
\hline$* *,, \varepsilon \wedge \mu$ & 17 & $*, r q r$ & 10 & $* *,, 0 \leqslant 1$ & $1 \varepsilon$ & $* *,, 009$ & Ir \\
\hline,, $1 \leq 7$ & IV & $*, r \bullet 1$ & 19 & $* *,, \diamond \wedge \varepsilon$ & 11 & $* *,, \varepsilon, q$ & $r$ \\
\hline., 190 & $r r$ & $* *,, \wedge \wedge \uparrow$ & rr & $* *,, 0 \leq r$ & Yl & $* *,, \varepsilon \vee ५$ & $Y \varepsilon$ \\
\hline$* *,, \leq 9 \leq$ & rq & $*^{*},, \leq \vee \leq$ & $r$. & $* *$, , $\{9 \leq$ & ro & $* *,, 0 \leq 1$ & $r \wedge$ \\
\hline$\cdot, \wedge v$ & rv & $* *, \wedge \uparrow$. & ع & , r. . & rq & $* *,,\{91$ & rr \\
\hline$* *,, \mu \circ q$ & r & $* *, \wedge \vee \wedge$ & rی & $* *, v, r$ & r & $* *, \Delta \mu_{0}$ & $\varepsilon$. \\
\hline$* *,, 7 \mid \wedge$ & ro & $*, \mu / q$ & $\varepsilon 1$ & $* *,, r \vee 1$ & $\mu v$ & $* *,,\{\wedge \wedge$ & $\varepsilon r$ \\
\hline$* *,, \varepsilon r$. & q & $* *, \mu r v$ & $\varepsilon \varepsilon$ & & & $\cdot, r \leqslant Y$ & $\varepsilon 7$ \\
\hline$* *,, r \wedge q$ & $r q$ & & & & & $* *,, r \wedge I$ & $\varepsilon V$ \\
\hline$* *, 0,1$ & $\varepsilon r$ & & & & & & \\
\hline$* *, \mu, r \vee V$ & $\varepsilon 0$ & & & & & & \\
\hline
\end{tabular}

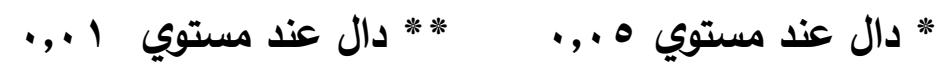

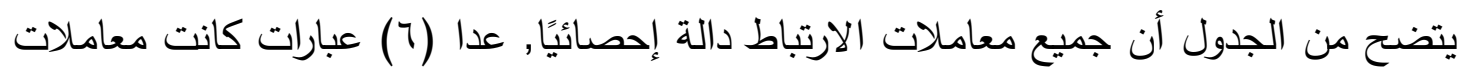

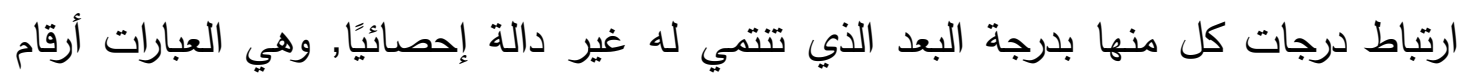

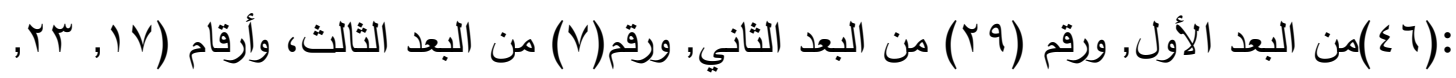

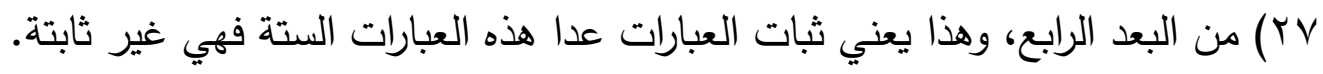


ثبات الأبعاد: تم حساب معاملات الارتباط بين درجات الأبعاد والدرجة الكلية للمقياس, والنتائج كما يلي:

جدول (IV) معاملات الارتباط بين درجات الأبعاد والدرجة الكلية لمقياس جودة الحياة (ن =

( 1.

\begin{tabular}{|c|c|}
\hline معامل الارتباط مع الدرجة الكلية للمقياس & أبعاد مقياس جودة الحياة \\
\hline$* *, \wedge \vee \bullet$ & جودة الحياة اللنفسية \\
\hline$* *, \wedge \leq q$ & جودة الحياة الاجتماعية \\
\hline$* *, \wedge \wedge \mu$ & جودة الحياة الأكاديمية \\
\hline$* *$, , AVr & جودة الحياة الجسمية \\
\hline
\end{tabular}

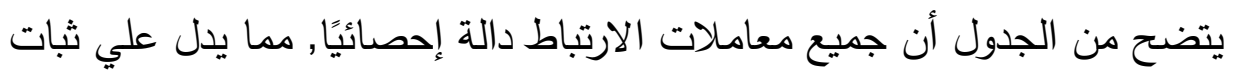

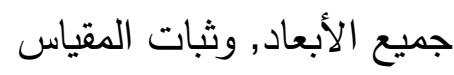

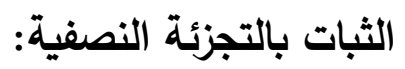

تم حساب ثبات الأبعاد والثبات الكلي للمقياس بالتجزئة النصفية، حيث (ن= • 7 طالبًا

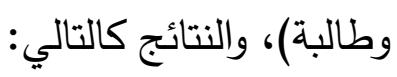

جدول (1) معاملات الثبات بالتجزئة النصفية للأبعاد واللارجة الكلية لمقياس جودة الحياة

\begin{tabular}{|c|c|c|}
\hline الثبات بمعادلة جتمان & الثبات بمعادلة سبيرمان/ براون & جودة الحياة \\
\hline סזץ, & וז7, & جودة الحياة النفسية \\
\hline$\cdot, v \cdot r$ & $\cdot, v \cdot q$ & جودة الحياة الاجتماعية \\
\hline$\cdot, \Lambda \mid r$ & $\cdot, \wedge) \leq$ & جودة الحياة الأكاديمية \\
\hline ( & , OrY & جودة الحياة الجسمية \\
\hline$\cdot, \wedge 9 \wedge$ & $\cdot, \wedge ৭ \wedge$ & الارجة الكلية لجودة الحياة \\
\hline
\end{tabular}

يتضح من النتائج السابقة أن قيم معاملات الثبات مرتفعة نسبياً مما يدل علي ثبات جميع

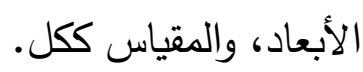

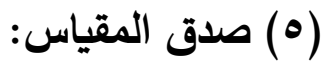


تم حساب الصدق بحساب معاملات الارتباط بين درجات العبارات والدرجة الكلية للبعد الذي تتنمي له (محذوفًا منها درجة العبارة), باعتبار مجموع درجات بقية العبارات محكًا للعبارة

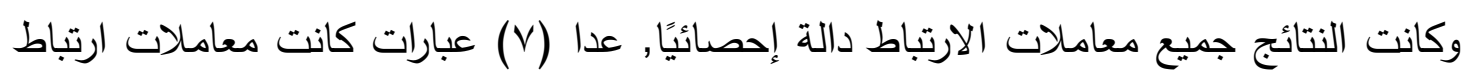

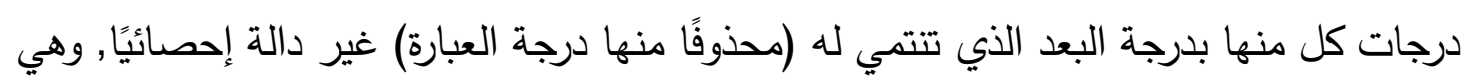

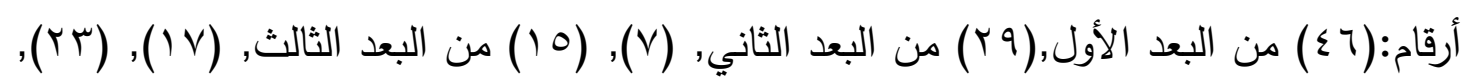

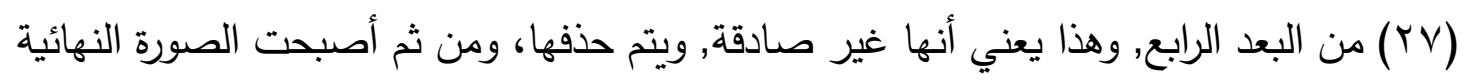

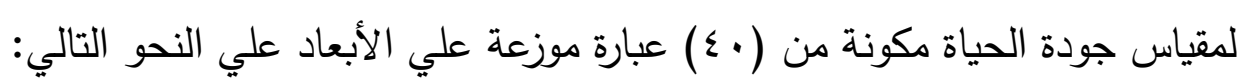

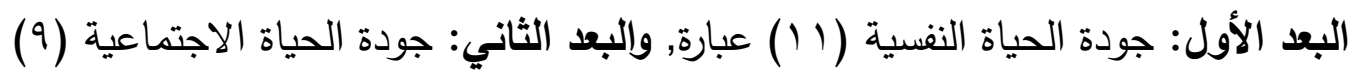

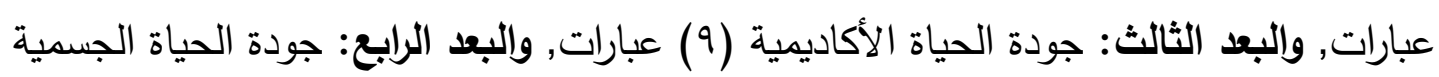
(1 (1) عبارة, وهذه الصورة صالحة للتطبيق علي العينة الأساسية في البحث الحالي. نتائج البحث نتائج الفرض الأول وتفسيرها ومناقثتها: ينص الفرض علي أنه: تتباين مستويات وترتيب درجات أبعاد مقياس التشوهات المعرفية لاي طلبة الصف الثاني الثانوي العام. ولاختبار هذا الفرض تم حساب المتوسطات الحسابية والانحرافات المعيارية لدرجات

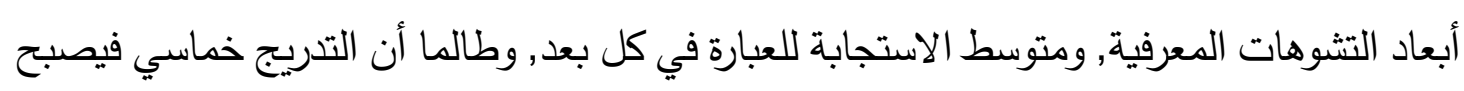

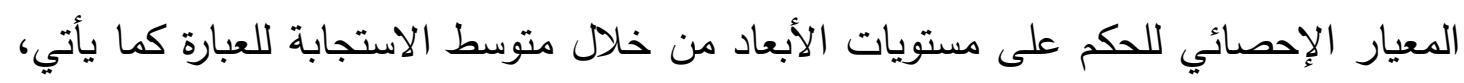

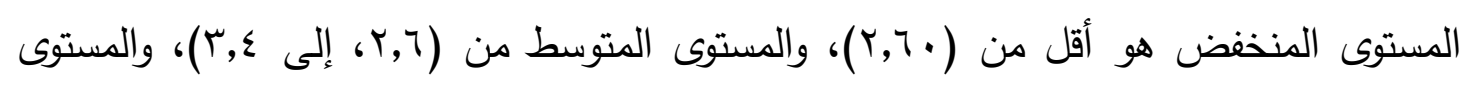

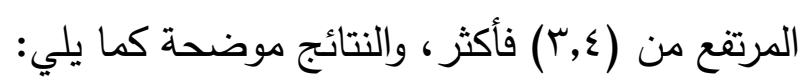


جدول (r (r) المتوسطات الحسابية والانحرافات المعيارية ومتوسطات الاستجابة للعبارات في كل بعد، وترتيب الأبعاد لمقياس التشوهات المعرفية لاي طلبة الصف الثاني الثانوي العام.

\begin{tabular}{|c|c|c|c|c|c|c|}
\hline المستوى & الترتيب & المتوسط الوزني & الالمعراف & الحسابي & العبارات & التشوهات المعرفية \\
\hline متوسط & 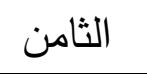 & $r, \wedge \wedge$ & $\varepsilon, .99$ & $1 \wedge, \Delta r \leqslant$ & 9 & (1) تفكير الكل أو لا شيء. \\
\hline متوسط & 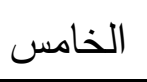 & $r, Y \wedge \varepsilon$ & $r, . \varepsilon$. & Ir,IrV & $\varepsilon$ & (r) الشخصنة واللوم. \\
\hline متوسط & 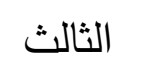 & r,r, & $r, .9 V$ & Ir,rAo & $\varepsilon$ & (r) التفكير الكارثي. \\
\hline مرتفع & 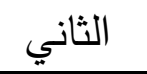 & $r, \varepsilon r q$ & $r, V \leq r$ & $1 r, v 00$ & $\varepsilon$ & ( ) الينبغيات. \\
\hline متوسط & التاسع & $r, . \leq q$ & $r, 0 \wedge \Lambda$ & $10, r \leqslant 0$ & • & (•) التجريد الانتقائي. \\
\hline متوسط & العاشر & r,qVi & $0, . \vee 7$ & $r \cdot, v q q$ & $v$ & (†) التعميم الزائد. \\
\hline متوسط & 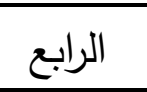 & $r, \mu, \varepsilon$ & $r, \wedge \bullet q$ & rr, 19V & $v$ & (V) التهويل أو التهوين. \\
\hline متوسط & السابع & $r, 1 \cdot \varepsilon$ & $r, v \wedge v$ & 10,orr & 0 & (^) العناوين المضللة. \\
\hline متوسط & السادس & $r, 191$ & r,Y04 & IY,VTr & $\varepsilon$ & (9) الاستنتاج العشوائي \\
\hline مرتفع & الأول & $r, 0 \leqslant 9$ & $r, r \leqslant Y$ & $1 \cdot, T \leqslant V$ & $r$ & ( • (1) الحكم الانفعالي \\
\hline متوسط & & $r, r \ldots$ & $19,9 \vee \leq$ & $107, \Lambda \cdot r$ & $\leqslant 9$ & الارجة الكلية \\
\hline
\end{tabular}

يتضح من الجدول السابق أن:

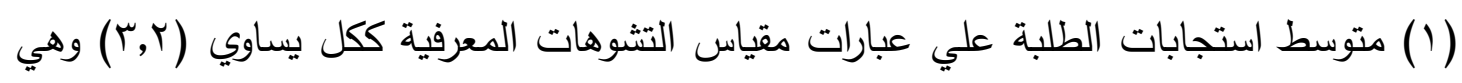
تدل على أن مستوى التشوهات المعرفية لاى أفراد العينة متوسط.

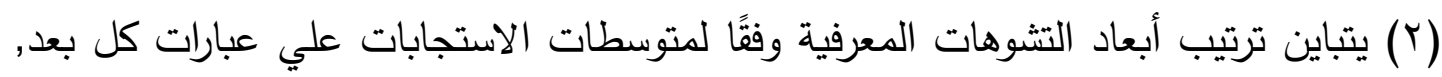
وكانت أعلي ثلاثة أبعاد في الترتيب هي: الحكم الانفعالي, والينبغيات, والتفكير الكارثي,

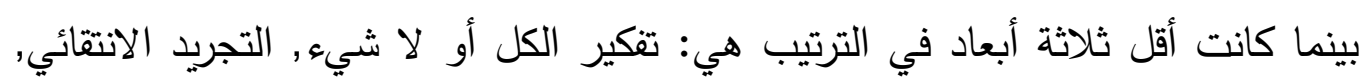

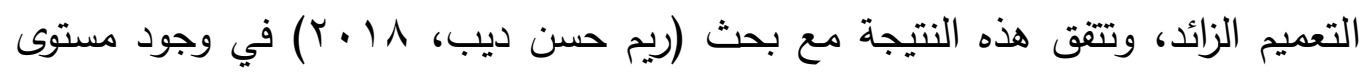
متوسط من التشوهات المعرفية.

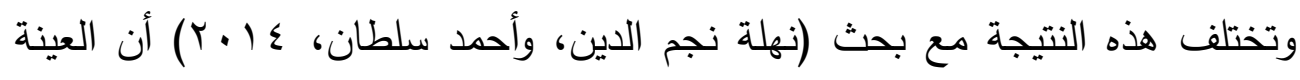

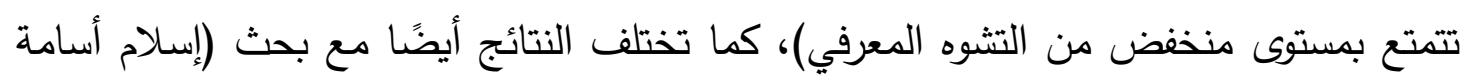

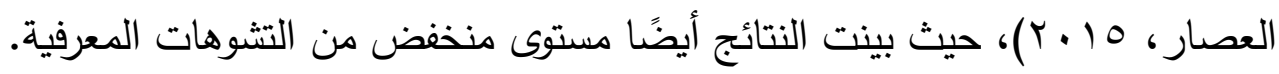

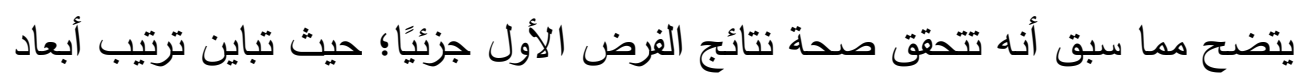
التشوهات المعرفية لدى عينة البحث، وكان مستوى الدرجة الكلية للتشوهات المعرفية وأبعادها 
الفرعية متوسطًا لديهم فيما عدا الينبغيات والحكم الانفعالي، ويمكن تفسير أن مستوى التشوهات

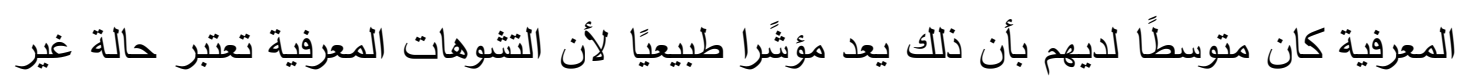

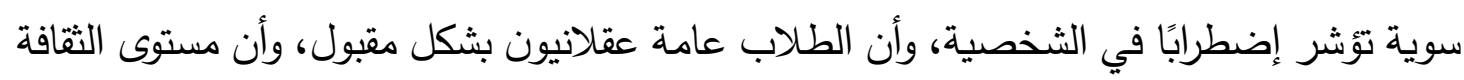

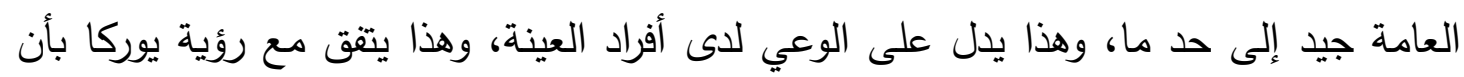

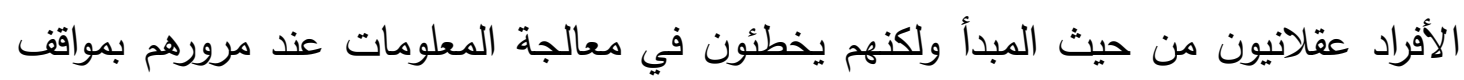

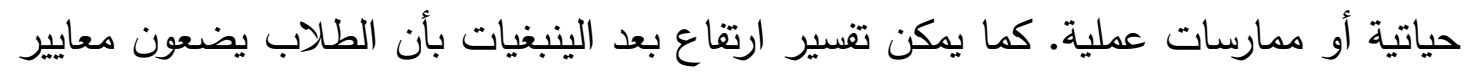

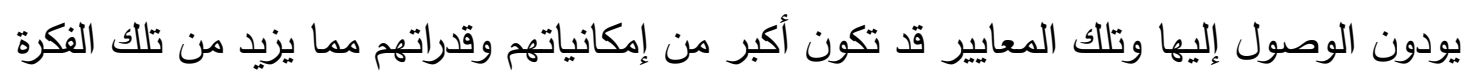

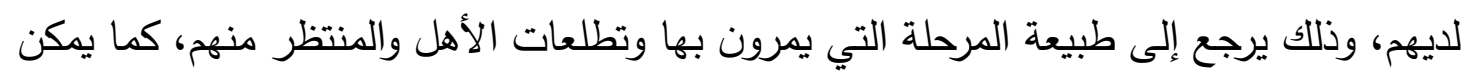

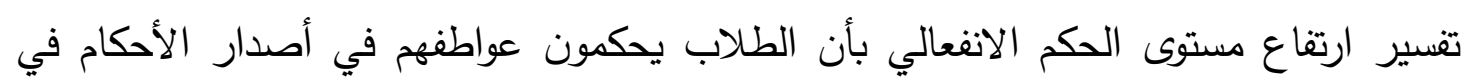
المواقف المختلفة.

كما يمكن تفسير ذلك التباين في ترتيب أبعاد التشوهات المعرفية لدى الطلاب لعدة

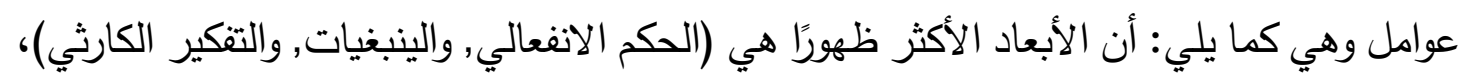

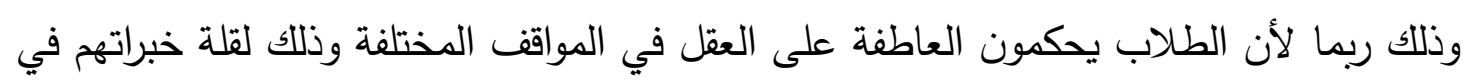

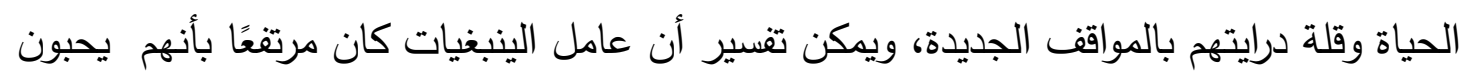

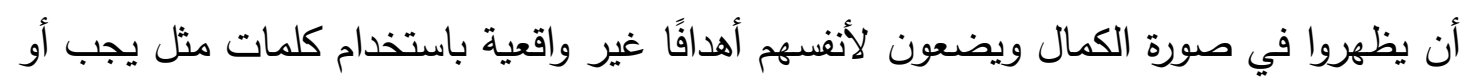

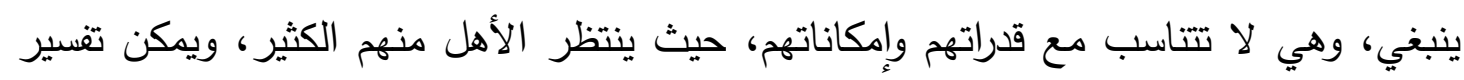

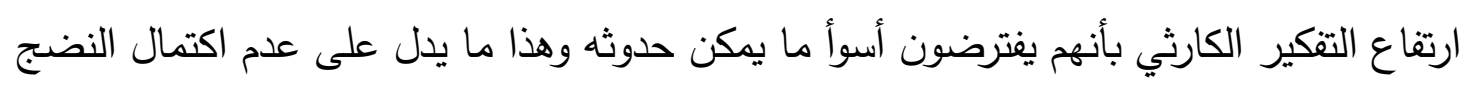

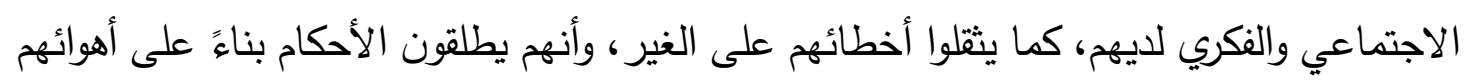

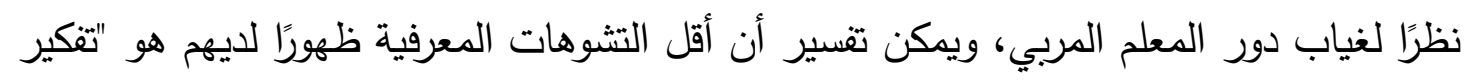

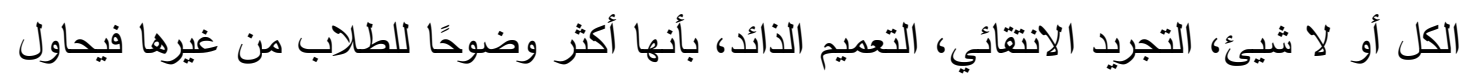
الطلاب تجنبها، وبالتالي يمكن أن يعزى اختلاف ترتيب عوامل التشوهات المعرفية إلى طبيعة التئي

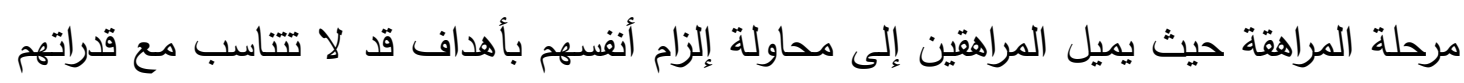
والمبالغة في المعايير • مرحل

\section{نتائج الفرض الثاني وتفسيرها ومناقشتها:}

ينص الفرض الثاني علي أنه لاتوجد فروق ذات دلالة إحصائية بين متوسطات درجات ومات الأكور والإناث في مقياس التشوهات المعرفية لاي طلبة الصف الثاني الثانوي العام.

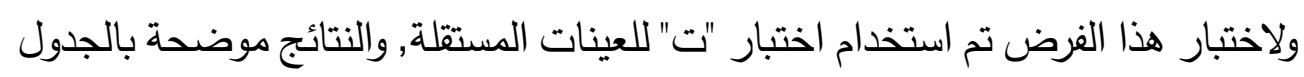


جدول (Y Y نتائج اختبار"ت" لالالة الفروق بين متوسطات درجات الذكور والإناث

علي مقياس التشوهات المعرفية لاى طلبة الصف الثاني الثانوي العام.

\begin{tabular}{|c|c|c|c|c|c|c|}
\hline |مستوي الدلالة & قيمة "ت" & الانحراف المعياري & المتوسط & العدد & المجموعة & التشوهات المعرفية \\
\hline غير دالة & $\cdot, \varepsilon \wedge \leq$ & $\begin{array}{l}r, 991 \\
\varepsilon, \varepsilon \cdot \varepsilon\end{array}$ & $\begin{array}{l}\mid \Lambda, \leqslant \vee r \\
|\Lambda, Y|\end{array}$ & $\begin{array}{l}94 \\
10 \mathrm{~V}\end{array}$ & الإلكور & (1) تفكير الكل أو لا شيء \\
\hline غير دالة & $\cdot, 9 \wedge 9$ & $\begin{array}{l}r, q r V \\
r, . q r\end{array}$ & $\begin{array}{l}\mid r, r r r \\
\mid r, q \leq r\end{array}$ & $\begin{array}{l}94 \\
10 \mathrm{~V}\end{array}$ & الإناث & (r) الثخصنة واللوم \\
\hline غير دالة & $\cdot, \vee \vee q$ & $\begin{array}{l}r, 19 \varepsilon \\
r, q Y o\end{array}$ & $\begin{array}{l}\mid r, r q \wedge \\
1 r, . \wedge q\end{array}$ & $\begin{array}{l}94 \\
10 \mathrm{~V}\end{array}$ & الإناث & (ץ) التفكير الكارثي \\
\hline غير دالة & $\cdot, \wedge \vee r$ & $\begin{array}{l}r, V \vee I \\
r, Y 4 \Lambda\end{array}$ & $\begin{array}{l}\mid r, 0 q 1 \\
1 r, q .0\end{array}$ & $\begin{array}{l}94 \\
10 \mathrm{~V}\end{array}$ & الإناث & ( ) الينبغيات \\
\hline$\cdot, .0$ & Y,६१ & $\begin{array}{l}r, \leqslant \leqslant V \\
r, 0 \leqslant q\end{array}$ & $\begin{array}{l}10, \wedge Y \wedge \\
1 \leq, V Y Y\end{array}$ & $\begin{array}{l}94 \\
\text { 10V }\end{array}$ & الإناث & (•) التجريد الانتقائي \\
\hline غير دالة & $1,7 \cdot V$ & $\begin{array}{l}0, \cdot \leq \vee \\
0, Y q \leq\end{array}$ & $\begin{array}{l}r, \leqslant \leq 90 \\
r ., \leqslant 1 \leqslant\end{array}$ & $\begin{array}{l}9 \mathrm{r} \\
10 \mathrm{~V}\end{array}$ & الإلإثور & ( آ) التعميم الزائد \\
\hline غير دالة &.,$O \vee V$ & $\begin{array}{l}\varepsilon, \varepsilon q 0 \\
r, v \cdot r\end{array}$ & $\begin{array}{l}r Y, \wedge Y \wedge \\
r r, I \leqslant V\end{array}$ & $\begin{array}{l}94 \\
10 \mathrm{~V}\end{array}$ & الإناث & التهويل أو التهوين (v) \\
\hline غير دالة & $\cdot, \cdot r \leq$ & $\begin{array}{l}r, \wedge Y \varepsilon \\
r, \uparrow \wedge \uparrow\end{array}$ & $\begin{array}{l}10, \leqslant 90 \\
10, \leqslant \vee \wedge\end{array}$ & $\begin{array}{l}94 \\
\text { lor }\end{array}$ & الإلكور & (^) العناوين المضلله \\
\hline غير دالة & $1, v r \varepsilon$ & $\begin{array}{l}\text { r,vro } \\
\text { r,TAV }\end{array}$ & 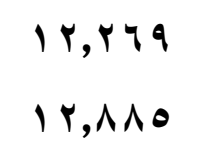 & $\begin{array}{l}94 \\
10 \mathrm{~V}\end{array}$ & الإناث & (9) الاستنتاج العشوائي \\
\hline غير دالة & $1, Y 1 \leq$ & $\begin{array}{l}r, I \leq Y \\
r, r q\end{array}$ & $\begin{array}{l}1 \cdot, \text { rq } \\
1 \cdot, V Y \text {. }\end{array}$ & $\begin{array}{l}94 \\
10 \mathrm{~V}\end{array}$ & الإناث & ( · ( ) الحكم الانفعالي \\
\hline غير دالة & $\cdot, \leqslant \Lambda$ & $\begin{array}{l}r, r q Q \\
\mid q, \Delta q 1\end{array}$ & $\begin{array}{l}107,17 . \\
100,017\end{array}$ & $\begin{array}{l}94 \\
10 \mathrm{~V}\end{array}$ & الإناث & الارجة الكلية \\
\hline
\end{tabular}

يتضح من الجدول أن جميع الفروق بين متوسطات درجات الذكور والإناث على الدرجة الكلية

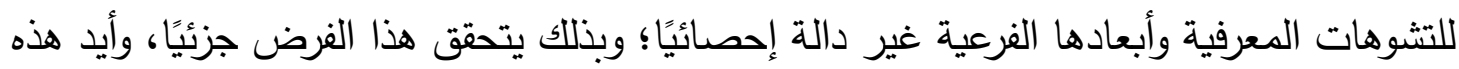

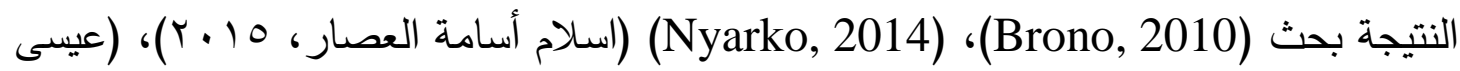

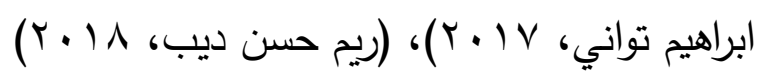




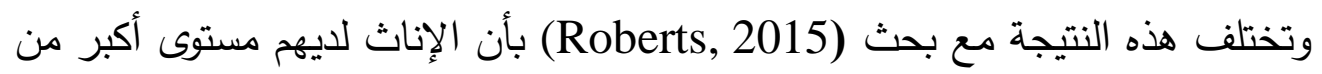

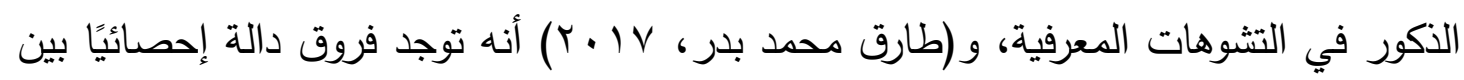
متوسطات درجاتهم لصالح الذكور • ويمكن تفسير نتائج هذا الفرض بأن كل من الذكور والإناث أصبح لديهم تصورات ومفاهيم متشابهه

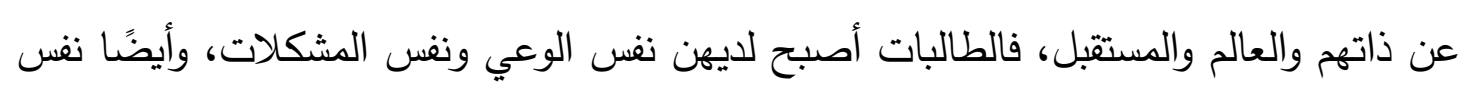

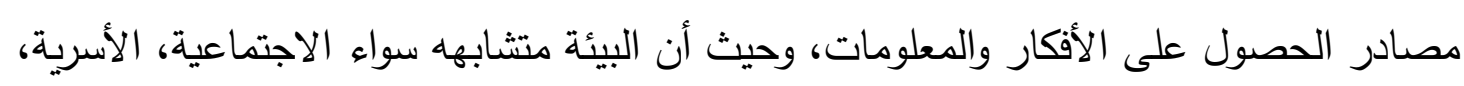

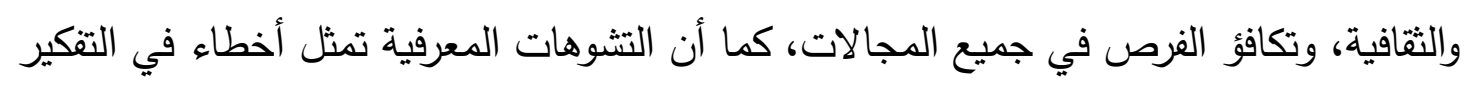

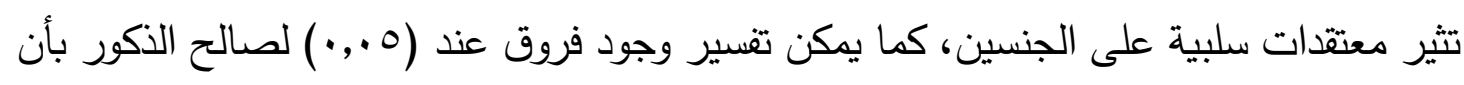
الذكور يميلون إلى النظر إلى الموقف وتفنيده والنظر إلى أجزاءه وتفاصيله والتركيز فيها.

نتائج الفرض الثالث وتفسيرها ومناقشتها:

ينص الفرض علي أنه "لاتوجد فروق ذات دلالة إحصائية بين متوسطات التات درجات

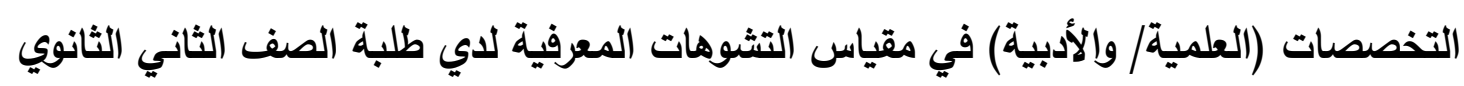

ولاختبار هذا الفرض تم استخدام اختبار "ت" للعينات المستقلة, والنتائج موضحة بالجدول

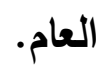

$$
\text { التالي: }
$$

جدول (Y Y نتائج اختبار "ت" لالالة الفروق بين متوسطات درجات التخصصات العلمي

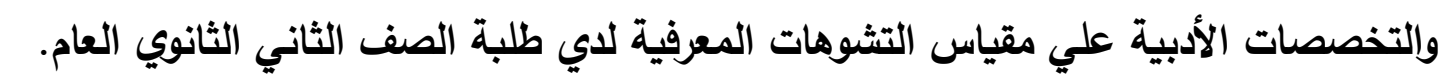

\begin{tabular}{|c|c|c|c|c|c|c|}
\hline مستوي الدلالة & قيمة "ت" & الانحراف المعياري & المتوسط & 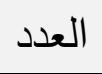 & المجموعة & التشوهات المعرفية \\
\hline \multirow[t]{2}{*}{ غير دالة } & \multirow[t]{2}{*}{$1, .09-$} & ס טr, & $|v, q|$ & $\wedge \vee$ & علمي & \multirow[t]{2}{*}{ (1) تفكير الكل أو لا شيء } \\
\hline & & $\varepsilon, Y \cdot \Lambda$ & $|1,0|$ & 19 & أدبي & \\
\hline \multirow[t]{2}{*}{ غير دالة } & \multirow[t]{2}{*}{$\cdot, 1 \leqslant 0$} & $r, V \wedge r$ & Ir,Ir & $\wedge \vee$ & علمي & \multirow[t]{2}{*}{ (r) الثخصنة واللوم } \\
\hline & & $r, I r v$ & $1 r, .9$ & 19 & أدبي & \\
\hline \multirow[t]{2}{*}{ غير دالة } & \multirow[t]{2}{*}{, ז. } & r,VAr & $1 r, . \leq$ & $\wedge \vee$ & علمي & \multirow[t]{2}{*}{ (r) التفكير الكارثي } \\
\hline & & $r, 10 r$ & $\mid r, r \leq$ & r & أدبي & \\
\hline \multirow[t]{2}{*}{ غير دالة } & \multirow[t]{2}{*}{$1, \wedge q r-$} & r, & $\mid r, r \leq$ & $\wedge \vee$ & علمي & \multirow[t]{2}{*}{ (ع الينبغيات } \\
\hline & & $r, \vee \sim q$ & $1 \leq, \cdot r$ & 19 & أدبي & \\
\hline \multirow[t]{2}{*}{ غير دالة } & \multirow[t]{2}{*}{ I, } & $r, r \leq q$ & $10,7 r$ & $\wedge \vee$ & علمي & \multirow[t]{2}{*}{ (0) التجريد الانتقائي } \\
\hline & & r,TVO & $1 \leq, \wedge \mathrm{V}$ & 174 & أدبي & \\
\hline غير دالة & , rVq- & $\varepsilon, \vee Y q$ & $r_{1, r}$ & $\wedge \vee$ & علمي & ( ( ) التعميم الزائد \\
\hline
\end{tabular}




\begin{tabular}{|c|c|c|c|c|c|c|}
\hline & & $\varepsilon,\{\odot \bullet$ & $Y \cdot, O r V$ & r & أدبي & \\
\hline غير دالة & $1,19 \mathrm{~V}$ & $\begin{array}{l}\varepsilon, \varepsilon \circ\urcorner \\
Y, \vee \neg \varepsilon\end{array}$ & $\begin{array}{l}r r, q r \\
r r, \cdot v\end{array}$ & $\begin{array}{l}\text { AV } \\
17 r\end{array}$ & علمي & التهويل أو التهوين (V) \\
\hline غير دالة & •, , rr & $\begin{array}{l}r, \neg \vee r \\
r, \vee V I\end{array}$ & $\begin{array}{l}10, \& 9 \\
10, \& V\end{array}$ & $\begin{array}{l}\text { Av } \\
17 r\end{array}$ & علمي & (^) العناوين المضللة \\
\hline غير دالة & $1, \wedge \vee 1-$ & $\begin{array}{l}r, \wedge Y I \\
r, \nearrow r q\end{array}$ & $\begin{array}{l}I Y, Y Y \\
\mid Y, \wedge \wedge\end{array}$ & $\begin{array}{l}\text { AV } \\
17 r\end{array}$ & علمي & (9) الاستتتاج العشوائي \\
\hline غير دالة & 1.rYq- & $\begin{array}{l}r, Y \mid l \\
r, Y V .\end{array}$ & $\begin{array}{l}1 \cdot, r \varepsilon \\
1 \cdot, v 1\end{array}$ & $\begin{array}{l}\text { Av } \\
17 r\end{array}$ & أدبي & ( • (1) الحكم الانفعالي \\
\hline غير دالة & - & $\begin{array}{l}19,1 \mid 1 \\
Y 1,1 Y \wedge\end{array}$ & $\begin{array}{l}\mid 00, \varepsilon \\
107, \mu\end{array}$ & $\begin{array}{l}\text { AV } \\
174\end{array}$ & أدبي & الدرجة الكلية \\
\hline
\end{tabular}

يتضح من الجدول السابق أنه: لا توجد فروق دالة إحصائيًا في التثوهات المعرفية

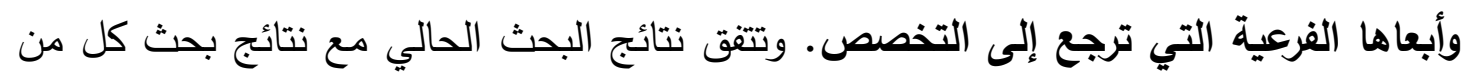

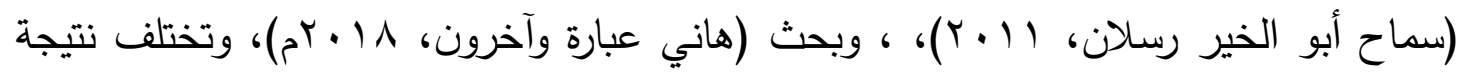

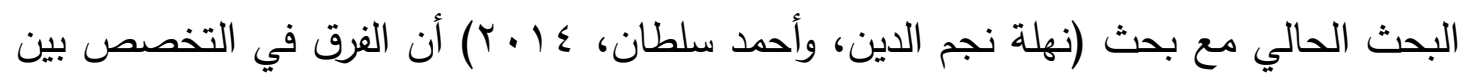

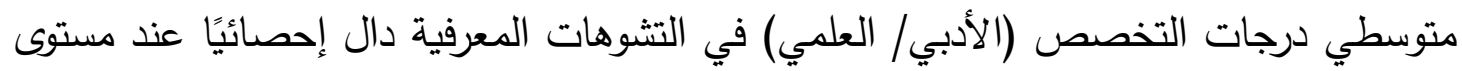
(0. (. •) ولصالح التخصص الأدبي ويمكن تفسير هذه النتيجة بأن الأفكار والمعتقدات لاى طلاب كلا التخصصين شبه

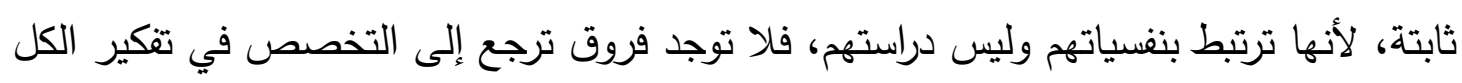

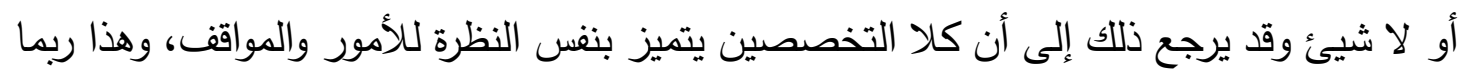

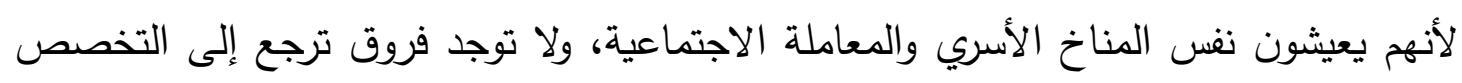

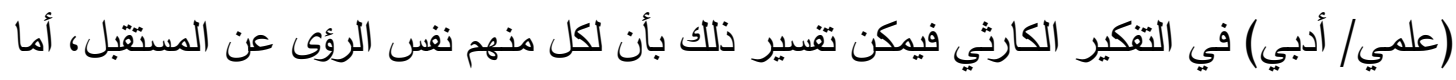

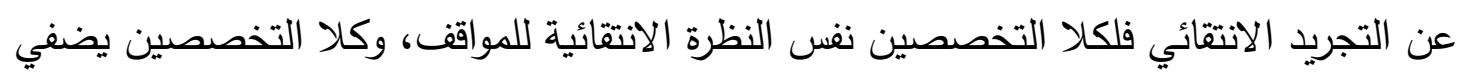

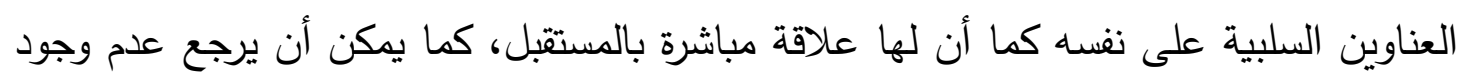

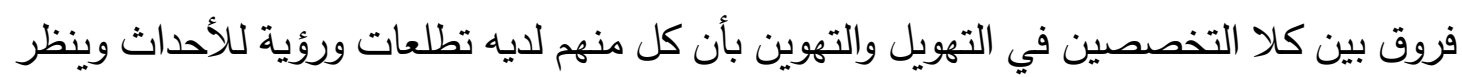
إليها بنفس الطريقة، ويرجع عدم وجود فروق بين طلاب كلا التخصصين في التشوهات المعرفية

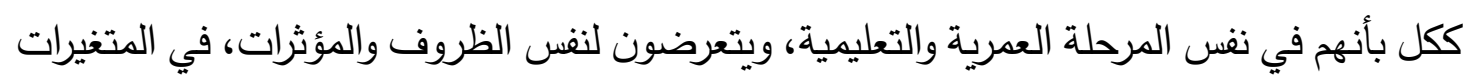
التي تطرأ عليهم، وطريقة تفاعلهم وحالتهم النفسية وكذلك أسلوبهم في الحياة. 


\section{• أنتائج الفرض الرابع وتفسيرها ومناقشتها:}

ينص الفرض على أنه:"يوجد ارتباط سالب ذا دلالة إحصائية بين التشوهات المعرفية

وجودة الحياة

ولاختبار هذا الفرض تم استخدام معامل الارتباط (بيرسون)، والنتائج موضحة بالجدول

جدول( ج م) معامل ارتباط "بيرسون" بين درجات التثوهات المعرفية بأبعادها الفرعية

والارجة الكلية، ودرجات جودة الحياة بأبعادها الفرعية والادرجة الكلية.

\begin{tabular}{|c|c|c|c|c|c|}
\hline جودة الحياة & جودة الحياة & جودة الحياة & الاجتماعية الحياة & جودة الحياة & المتغير \\
\hline$\because,, 199-$ & *., 174- & *.,IFr- & $*, 171-$ & *., & تفكير الكل أو لا شيء \\
\hline$* * \cdot, r \cdot 1-$ & ***, & $\because \cdot, \mid \vee r-$ & $* * \cdot, r Y V-$ & ** , Y Y O- & نخصنة واللوم \\
\hline$* \because, r, r \cdot \%-$ & $* *, r, Y \circ V-$ & ***,r】V- & $* * *, Y \backslash V-$ & ***,YYYT & فكير الكارثي \\
\hline$*$, IrV & 况 & $* ., 1 \times 9$ & . & $\cdot, \cdot v \leqslant-$ & 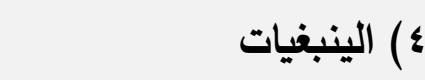 \\
\hline$* *, Y \Gamma 1-$ & $* *, r, r \leqslant 0-$ & 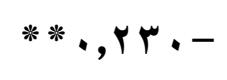 & $* \cdot, 1 \leqslant \Lambda$ &.,$. v \varepsilon-$ & 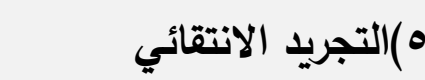 \\
\hline$\cdot, 1 \cdot r-$ &., $.90-$ & ., , $\leqslant \wedge-$ &., .09 &., $1 \ldots-$ & ليم يم الزائد \\
\hline$* *, 470-$ & $* *$ *, ए११- & $* *,, Y 99-$ & $* *, y \circ 1-$ & $* \cdot, 1 \leqslant r-$ & ئهويل أوالتهوين \\
\hline$* *, r \circ \Lambda-$ & $* *, r 10-$ & $* *$, , ro. - & $* *, Y Y \wedge \Lambda-$ & $\because$, YYA- & ضفاء العناوين. \\
\hline$*,, 1 \leqslant 1-$ & $*, 101-$ & $*,, i r v-$ & $\cdot, \cdot v \cdot-$ &., $.07-$ & تتنتاج العشوائي \\
\hline$* *, 17 \xi$ & $* *,|v|$ & ***, , $1 \wedge 4$ &., 111 &.,.$r$. & الحكم الانفعالي \\
\hline$* *, \Gamma Y \Lambda-$ & $* * \cdot, \Gamma 19-$ & ***,YTI- & ***,YYTH & $* *,, Y, q-$ & \\
\hline
\end{tabular}

يتضح من الجدول السابق ما يلي: 
يوجد ارتباط سالب دال إحصائيًا عند مستوى ( ( . . • بين التشوهات المعرفية ككل وجودة الحياة ككل وأبعادها الفرعية، وبذلك يتحقق هذا الفرض وتتفق نتائج البحث الحالي مع بحث (Odac1 ,et al, 2009) العامة، وأن التشوهات المعرفية الدرجة الكلية وأبعادها (التفكير الكارثي، الثخصنة، والتجريد الانتقائي)، ذات علاقة ارتباطية سالبة دالة إحصائيًا ( ( . •) بجودة الحياة لدى تلاميذ المرحلة

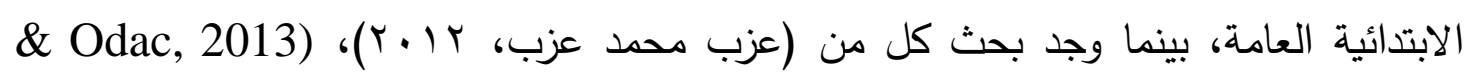
(Çelik

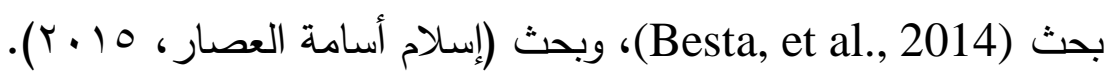
وتفسر الباحثة النتائج السابقة بأنه توجد علاقة سالبة دالة إحصائيًا بين تفكير الكل أو لا لألانها

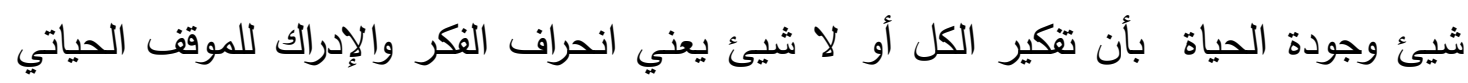
الاحساس بجودتها عمومًا، بينما توجد علاقة موجبة بين الينبغيات وجودة الحياة الأكاديمية وجودة الحياة ككل وذلك لأن الينبغيات تعتبر إلى مرحلة معينة شيئ إيجابي حتي إذا تعدت هذه المرحلة تصبح سلبية ومشوهه فهي تتخذ شكل المنحنى، وهي هنا تعتبر إيجابية مما يعزز جودة الحياة خاصة الأكاديمية حيث أن الطلاب في هذه المرحلة ينصب اهتمامهم وتفكيرهم من ناحية اليجبيات على الدراسة فهي هدف تلك المرحلة من التعليم، كما يمكن تفسير أنه لا توجد علاقة ارتباطية بين الينبغيات وجودة الحياة الجسمية، والنفسية، والاجتماعية، بأن تلك الأبعاد من الصعب وضع معايير ليتم الوصول إليها، ويمكن تفسير وجود علاقة سالبة دالة إحصائيًا بين التجريد الانتقائي وكل من (جودة الحياة الأكاديمية، والجسمية، والدرجة الكلية) بأن التجريد الانتقائي يعبر عن انتقاء بعض دله أجزاء الموقف السلبية والتركيز عليها وبالتالي يؤدي إلى أخطاء وتدني الشعور بجودة الحياة، كما يمكن تقسير وجود علاقة موجبة مع جودة الحياة الاجتماعية ذلك لأن ذلك النوع من التشوه يمكن أن يكون المنقذ في العديد من المشاكل الاجتماعية، كما يمكن أن يتم تفسير وجود علاقة سالبة دالة إحصائًا بين التهويل والتهوين وجودة الحياة ككل ماعدا جودة الحياة النفسية بأنها تؤدي إلى تدني جودة الحياة وهذا ما يفسر تلك العلاقة، كما توجد علاقة سالبة دالة إحصائيًا بين إضفاء العناوين وجودة الحياة ككل، وأبعادها الفرعية وذلك أن إضفاء العناوين السلبية للفرد على ذاته أو العالم أو المستقبل مثل أن ينعت نفسه بالغبي أو بالفشل أو العالم بأنه لا أهمية له فذلك يعزز المشاعر السلبية التي تؤدي إلى تقليل جودة الحياة. كما يمكن تفسير وجود علاقة سالبة دالة إحصائيًا بين الاستنتاج العشوائي، وجودة الحياة الأكاديمية، والجسمية، والدرجة الكلية لجودة الحياة، بأن الاستنتاج العشوائي يؤثر عكسيًا بدرجة

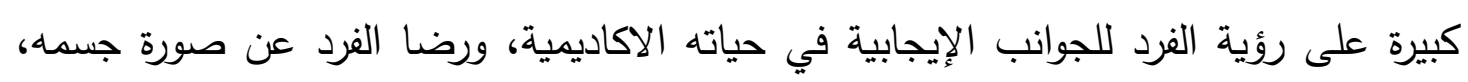
وصحته عامة، مما يؤثر سلبًا على جودة حياته، وتتوافق هذه النتائج مع الرؤية العامة للحياة، 
فالتفكير هو أساس الجودة وتبين "رايف" أن جودة حياة الفرد تكمن في قدرته على مواجهة الأزمات

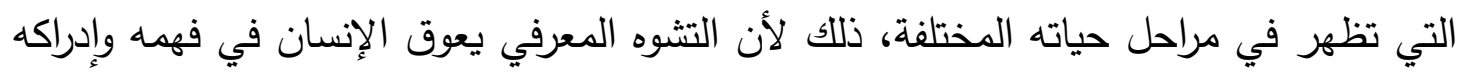
للأحداث وللمواقف التي تمر عليه. توصيات البحث:

بناء على ما أسفرت عنه نتائج البحث الحالي عن أهمية متغيرات البحث الثثلاثة التشوهات

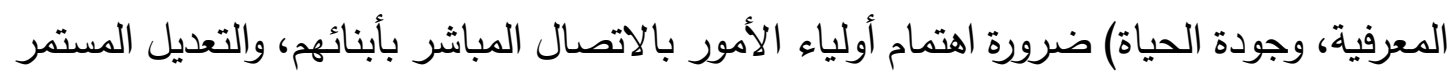
لما يظهر من سلوكيات ناتجة عن بعض تلك التشوهات المعرفية. محاولة إثراء المناهج الدراسية بدروس في اللغة العربية أو مسرحيات تتضمن التشوه المعرفي وتعديله بطريقة مشوقة وفنية.

توعية الشباب وتعزيز نظرتهم الإيجابية المستقبلية وجودة حياته، والحد من نظرتهم

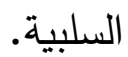

العمل على تطوير المناهج بما يضمن الجوانب (الوجدانية، الانفعالية، والسلوكية) للطالب

والاهتمام ببرامج التفكير من خلال تضمينها في الخطة السنوية للمرشدين النفسيين. عمل ندوات وورش عمل وإلقاء محاضرات تتعلق بتوضيح وسبل التغلب على التشوهات المعرفية وجودة الحياة.

عمل برامج للتغلب على التشوهات المعرفية، توضح الأفكار التلقائية والتشوهات المعرفية

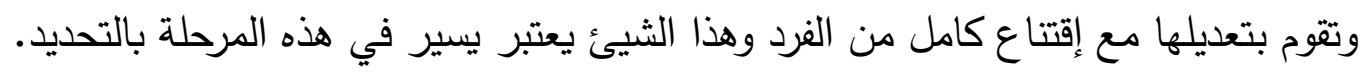
تضمين المناهج الدراسية دورات تثقيفية للطلاب وذلك لتحسين المرونة العقلية واستخدام مبدأ الوسطية في التعامل، بدلًا من التطرف في الحكم والتعامل الصحيح في المواقف والأحداث

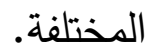

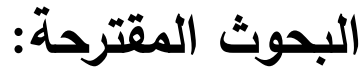

بحث التشوهات المعرفية لدى عينات أخرى من مراحل تعليمية مثل التعليم الإعدادي، أو

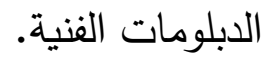

بحث التشوهات المعرفية وعلاقتها أساليب التفكير لاى طلبة الثانوية العامة.

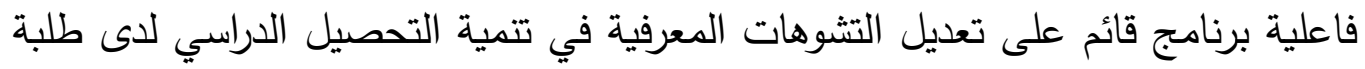

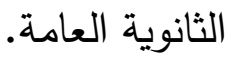

دراسة التشوهات المعرفية في علاقتها بإنكالية استخدام الانترنت لدى عينات متتوعة. العوامل الخمسة الكبرى للثخصية وعلاقتها بالتشوهات المعرفية في لدى طلبة المرحلة 
التشوهات المعرفية لدى مرتفعي ومنخفضي جودة الحياة من طلبة المرحلة الثانوية.

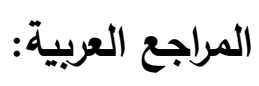

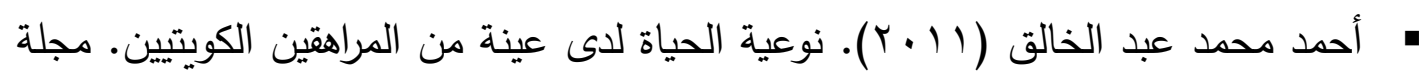

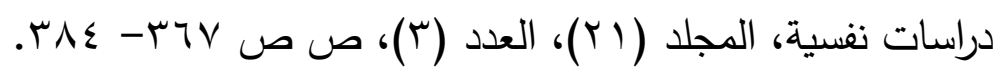

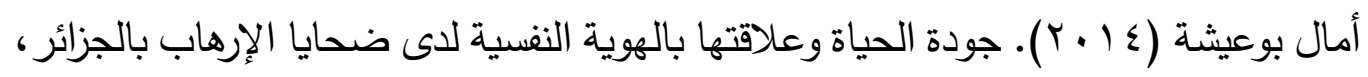

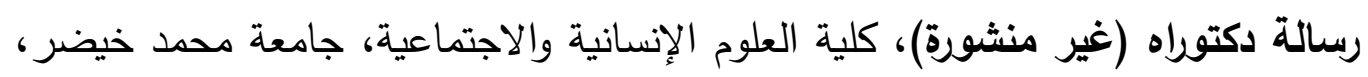

الجزائر .

O بشرى عناد مبارك (Y (Y). جودة الحياة وعلاقتها بالسلوك الاجتماعي لاى النساء

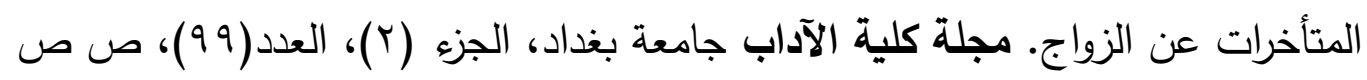
.VVI $-V 10$

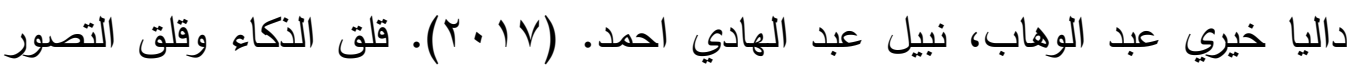

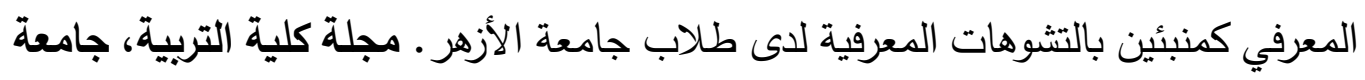

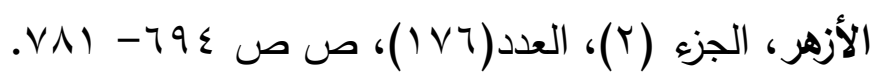

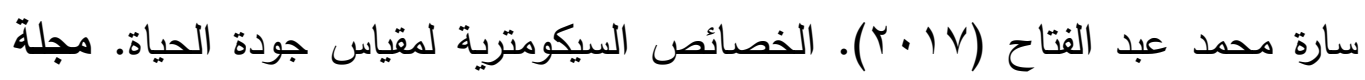

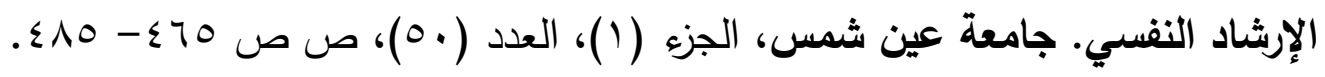

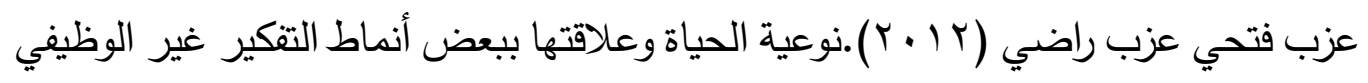

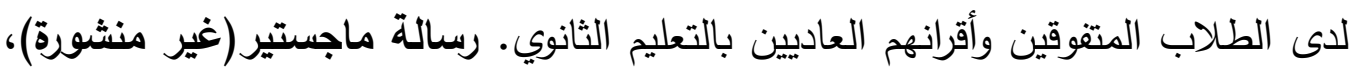
معهد الدراسات التربوية، جامعة القاهرة، مصر .

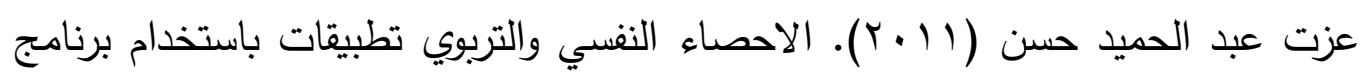
هSS 18 عيسى إبراهيم تواني (Y. V) (Y). علاقة المخطططات المبكرة غير المتكيفة بالتشويهات

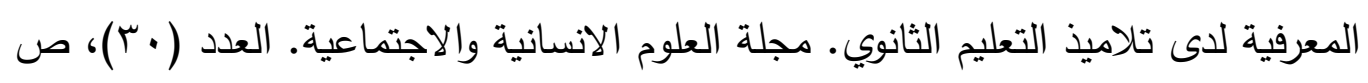
ص V.rفوزية علي داهم (ع (ب). جودة الحياة وعلاقتها بالأفكار اللاعقلانية المرتبطة بقلق الامتحان لدى تلاميذ السنة الثالثة ثانوي. رسالة ماجستير(غير منشورة)، جامعة الثهيد

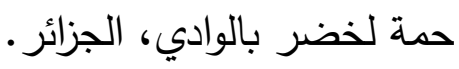

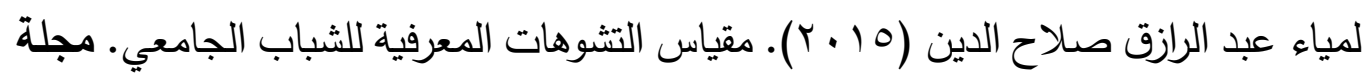

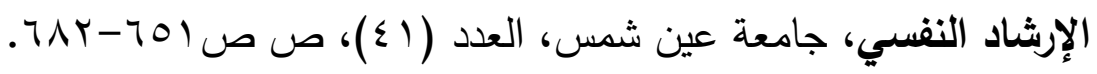




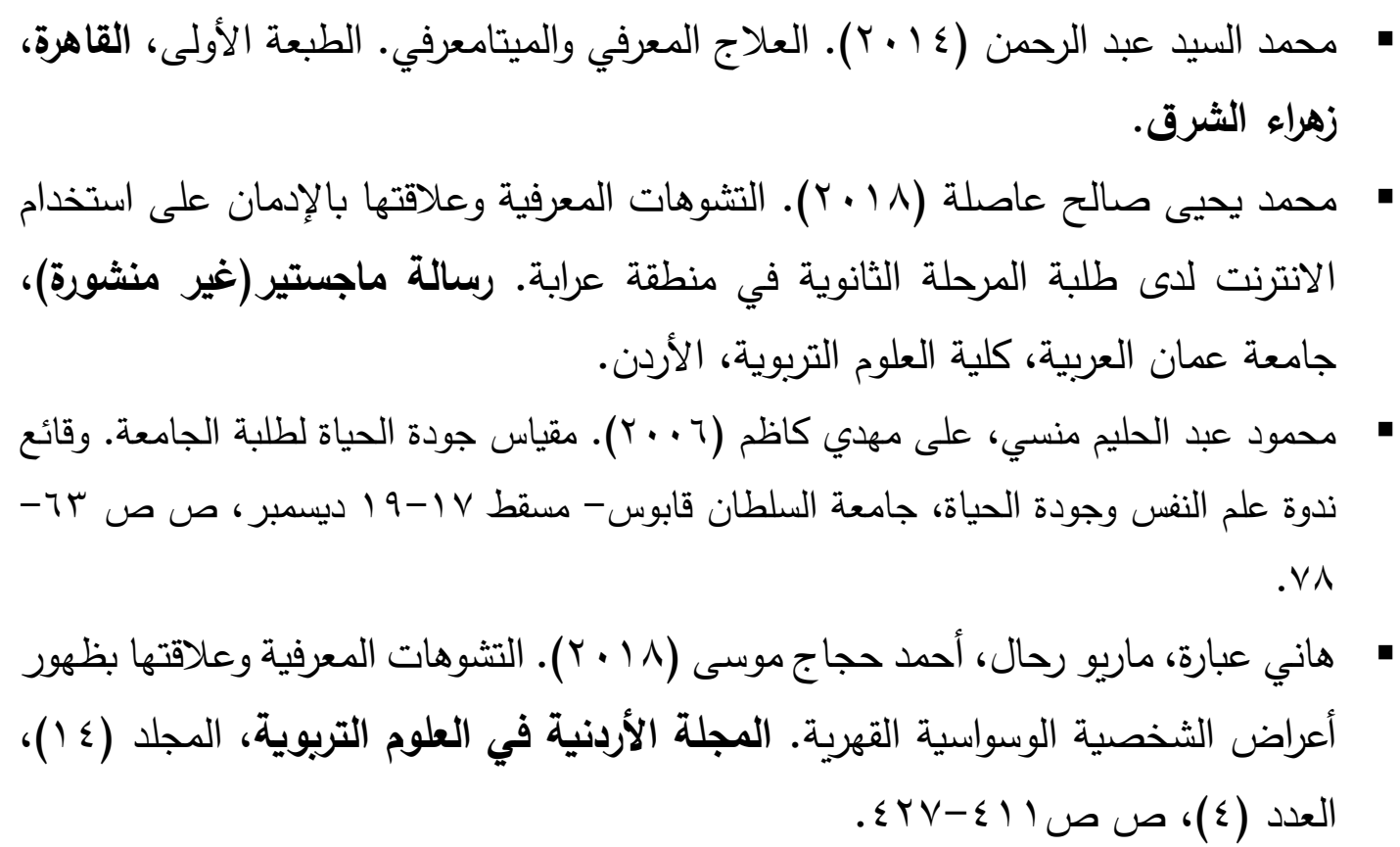

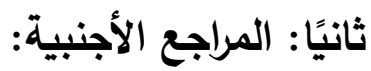

- Ara, E. (2016). Measuring Self-Debasing Cognitive Distortions in youth. International Journal of Asian Social Science, vol. 6, No. 12, Pp. 705712.

- Beak, A. Weismann, N. (1978). Development and validation of dysfunctional attitude scale: A preliminary Investigation. Paper presented at the annual meeting of the American educational research association (62nd, Canada, TO, March 27-3).

- Besta, T. Barczak, A. Walter, A. Dozois, D. (2014). Polish version of the Cognitive Distortions Scale (CDS): Preliminary validation and personality correlates. Current issues in personality psychology, vol. 2, No. 3, Pp. 177- 183.

- Çelik, Ç.B, \& Odacı, H. (2013). problematic internet use and interpersonal cognitive distortions and life satisfaction in university students. Children and Youth Services Review, Vol. 35, No. 1, Pp. 505-508. 
- Garruba, K. (2015). The Role of Cognitive Distortions in Adaptation to Disability and Perceived Quality of Life in Spinal Cord Injury. Ph.D., Philadelphia College of Osteopathic Medicine.

- O'Brien, D. (2016). The Association of Cognitive Distortions, Problems with Self-Concept, Gender, and Age in Adults Diagnosed with AttentionDeficit/Hyperactivity Disorder (ADHD). Ph.D., Philadelphia College of Osteopathic Medicine.

- Odaci, H. Kalkan, M. Karasu, P. (2009). A Predictor Of Quality Of Life Of The Mainstreamed Elementary Students: Cognitive Errors. International Journal of Special Education, Vol. 24, No. 3, Pp. 57-62.

- Pereira, A ., Barros, L., \& Mendonça, D. (2012). Cognitive Errors and Anxiety in School Aged Children. psychology Reflexes e Critical, Lisboan, Vol. 25, No. 4, Pp. 817-823.

- Rosenfield, B. (2004). Relationship between Cognitive Distortions and Psychological Disorders across Diagnostic Axes. Ph. D., Philadelphia College of Osteopathic Medicine.

- Ryff, C. (1989). Happiness is everything or is it? exploration on the meaning of psychological well-being. Journal of personality and social psychology, vol. 57, No. 6, Pp. 1069- 1081.

- Schalock, R. (2000). Three Decades of Quality of Life. Focus on Autism and Other Developmental Disabilities. Journal of Hamill Institute on Disabilities, vol. 15, No. 2, Pp. 116- 127.

- Yurica, C. (2002). Inventory of Cognitive Distortions: Validation of psychometric instrument for the measurement of Cognitive distortions. Unpublished doctoral dissertation, Philadelphia college of Osteopathic Medicine.

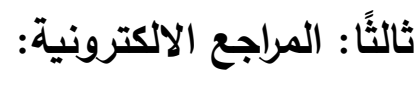




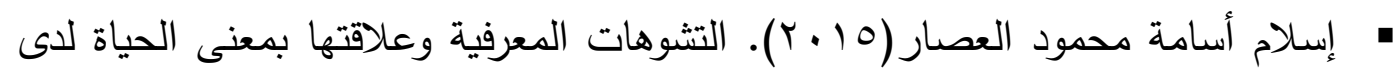
المراهتين بقطاع غزة. رسالة ماجستير(غير منشورة)، الجامعة الإسلامية، غزة. بتاريخ (11/T/10 